Article

\title{
The Roles and Measurements of Proximity in Sustained Technology Development: A Literature Review
}

\author{
Christian Omobhude * ${ }^{D}$ and Shih-Hsin Chen \\ Institute of Management of Technology, National Chiao Tung University, Hsinchu City 30010, Taiwan; \\ lbxshc@nctu.edu.tw \\ * Correspondence: chrisomobhude.mt04g@nctu.edu.tw
}

Received: 15 November 2018; Accepted: 28 December 2018; Published: 4 January 2019

\begin{abstract}
In existing studies, sustainable technology development involves harnessing knowledge assets to improve technological development and innovation to create competitive advantage for a firm. In recent decades, there has been a huge amount of scholarly articles on how technology development and innovation sustain competitive advantage. However, until recently most research focused on the spatial component of innovation and its influence on sustained technology development. Many studies have used proximity to examine spatial and relational mechanisms that lead to knowledge spillover and sustainable technology development. Reviewing 123 scholarly articles relating to proximity of innovation (1980-2018), this paper attempts to explore both spatial and non-spatial factors that influence sustainable technology and innovation development including geographic, cognitive, organizational, social, and institutional proximity. The review showed that each proximity dimension has relative importance and can be peculiar. For example, geographical proximity highlights the role of location and relative distance range in determining knowledge spillovers, especially relevant for face-to-face interaction and conditions that require certain types of complex tacit knowledge. This paper makes important contributions to our understanding of spatial and non-spatial proximity factors associated with sustainable technology development. The review showed that interpersonal factors are important for knowledge transfer to take place as knowledge does not depend entirely on location. The findings show that commonly used approaches to measure proximities include patent data and nomenclature of territorial units for statistics, not widely accessible across contexts, which impacts research and development (R\&D) policy development. Cognitive, social, and institutional dimensions are important for knowledge transfer, supported by interplay of other proximities that determine and influence sustained technology development. In addition, management of proximity influences how knowledge assets are used for innovation and sustained technology development.
\end{abstract}

Keywords: proximities; measurement indicators; sustainable technology development; knowledge spillover

\section{Introduction}

The current study reviews 123 scholarly articles on proximity (1980-2018) to organize and synthesize evidence of existing studies that have examined the roles and measurements of proximity in sustained technology developments. Knowledge transfer for innovation and sustained technology development is an important research area. It has been shown that knowledge provides sustainable technology development in many developed countries, as technology is relevant for sustainable development, and technology is an essential driver for sustainability and circular economy business 
models that creates tangible and intangible benefits in diverse activity sectors [1]. Developing successful technological innovation is required for sustaining a firm's competitive advantage [2]. In this sense, sustainable technology improves technological competitiveness of a firm and provides continuous growth $[3,4]$. There is evidence that sustainable technologies improve products, services, technological and organizational processes for better economic, environmental, and social performance in short and long term [2]. Therefore, selecting sustainable technologies is important to choose a target technology domain that enables a firm plan research and development policy efficiently [4]. Yet, it has been demonstrated that sustainable technology development is a holistic problem in which challenges are enormous for an organization to address in isolation [5], sustainable technology can be radical and transformational in nature [6] and requires breakthrough innovation changes [7]. Therefore, firms must engage in innovation activities to attract knowledge and technological inflow from outside [8], through innovation networks that exchange and integrate knowledge [9]. The network of companies and collaboration among entities is instrumental to develop innovative solutions and strategies for sustained technology development [10], such that actors use and combine knowledge from internal and external sources [11]. Firms can participate and obtain value from different outside sources such as suppliers, customers, competitors, consultants, universities, research centers, NGOs, and communities [12-14]. This assumes proximate people who are close (or near) are more likely to collaborate and easily communicate with one another.

As innovation and sustainable technology increasingly become a topic of concern, growing number of studies examine the roles of proximity in terms of spatial and non-spatial factors. However, mixed results suggest prior research is not conclusive. Proximity has been shown as exclusively geographical concept and has frequently focused primarily on a particular type of proximity [15]. In contrast, it has been argued that different proximities (geographical, cognitive, organizational, social, and institutional) are important for sustainable technology development [16-18]. On the contrary, studies have highlighted that a particular proximity dimension is neither beneficial nor detrimental for sustained technology development, but some factors characterize effects of proximity [19]. As a result, little is known about collective effects of spatial and non-spatial proximity dimensions, even though circumstances can require multiple proximity dimensions. Therefore, a literature review was conducted to organize and analyze all relevant empirical papers on proximities as it relates to enabling sustained technology development, through structured search for relevant literature.

The purpose of the current study was to examine the roles of proximity in sustained technology development using a literature review to organize and synthesize scholarly articles on proximity to provide deeper understanding for policymakers, managers, and researchers. Therefore, in the current study, we seek to answer the following research question: What are the roles of proximities in sustainable technology development? This is divided into two sub-questions below.

(1) How were innovation proximities defined and measured in existing literature?

(2) What are the roles of proximities while developing innovation networks for sustained technology development?

This review contributes to more understanding of how proximities are conceptualized in existing scientific articles, and how proximity influence sustained technology development. In addition, measurement indicators reviewed and recommended in the current study addresses the call for measures that can be used in context where certain data types are not readily available and less standardized [20-24].

The structure of the article is as follows: the second section briefly outlines the theoretical background that explains proximities, while the third section describes the method for conducting the literature review. The fourth section introduces the findings of the literature review. Thereafter, the fifth section discusses the findings and answers the research question. The sixth section outlines implication for practice and research, and finally we provide some concluding remarks for the current study. 


\section{Theoretical Background}

The relationship between geographical proximity of actors and sustained technology development has been widely researched in the field of economic geography, to understand how spatial factors influence innovation [3]. Technological spillovers are not negligible and influences non-decreasing returns at spatial aggregate levels [4]. These studies argue that regional resources such as labor market regulations, supplier networks, regional competencies, and regional institutions are favored by spatial-geographical factors $[1,25]$. Research on geography of innovation and production identify significance of spatial factors, and externalities on technological spillover between university researchers, industry research and development (R\&D), and skilled labor [5]. Therefore, it has been assumed that geographical proximity is beneficial to sustained technology development [8]. However, this view has recently been challenged. Existing studies have narrowly viewed spatial character of firms and their territories, and spatiality has been simplistically assumed as domestic [6]. In addition, "Neighbors might ignore or even hate one another. Local firms can be rivals and refuse any cooperation" [7]. Interactions among economic agents improve understanding of dynamic technological development and innovation in regions [26]. In other words, complementary formal and informal relationships provide insight into mechanisms that facilitate knowledge transfer, as individuals and institutions interact and cooperate in a synergy way that gives rise to knowledge spillovers. A range of spatial and non-spatial factors influence interaction that lead to knowledge spillover for sustained technology development.

It has been argued that dissimilarities between actors, regardless of spatial location, facilitates synergies for complementarities that influence collaboration [9]. Based on these divergent perspectives, this study conducts a literature review to investigate how, in addition to spatial factors, non-spatial proximity influences sustained technology and innovation development. As a result, we aim to understand spatial and non-spatial factors that affects knowledge spillover for sustained technology development, as scholars have suggested that proximity dimensions are mechanisms for collaboration $[10,12,13]$. The proximities are mainly geographical, cognitive, organizational, social, and institutional [10], economic (capital and intellectual resources) and social (constituted social or individual networks that mutually constructs knowledge) dimensions [14], which fit well within existing non-spatial dimensions (cognitive and social dimensions respectively).

\section{Methods}

The purpose of the current study is to provide deeper understanding on key issues and concepts on proximities for sustained technology development. A literature review was required to examine current knowledge, assemble, and organize scattered findings to provide shared understanding for the needs of researchers, policy makers, and managers involved in technology policy. Guided by the research purpose as mentioned above, we used principles provided by Cooper [11] and Seuring and Müller [16] to identify eligible studies for the current study. All relevant academic articles were retrieved from three scientific databases: Google Scholar, Scopus, and Web of Science. The time range for analysis was January 1980 to October 2018. The time range was selected to include one preliminary study [17] on proximity that started debates about spatial proximity, and to capture recent articles on the topic. This time range provides a broad view of contributions made on the topic of spatial and non-spatial proximities and influences on sustained technology development. The search for academic articles included two search strings that targets the title, abstract or keywords of academic publications, namely: (1) "Proximity AND Innovation OR Sustain OR Spillover" and (2) "Proximity AND Technology OR Favor OR Preserve." The search strategy was used to include articles with the term proximity, as well as other terms aligned with the purpose of the current study. In addition, we then reviewed references of retrieved articles to verify relevant contents that deserve further review based on the inclusion criteria explained as follows. Articles were selected according to relatedness to the main research question: what are the roles of proximities in sustainable technology development? This is addressed through the following sub-questions: 
- How were innovation proximities defined and measured in existing literature?

- What are the roles of proximities while developing innovation networks for sustained technology development?

In addition, to be included in the current study, the article would have been published in English language, and explains measurement indicators for proximity. Given diversity of measurement approaches that examined proximity, we identified and compared measurement indicators of reviewed articles. As summarized in Figure 1, we retrieved 509 academic articles by electronic database search. Of the total articles retrieved, 345 articles were excluded after screening the abstract and title of the articles, and 41 articles were excluded for being duplicates, unsuitable to the current study in terms of insufficient data, research design, language, or not being relevant to answer the research question of the current study. Finally, 123 articles were found eligible for the review based on the inclusion criteria, and the guiding research question. We manually coded all 123 articles using each proximity dimension as the main category to identify recurring themes, patterns for each category (proximity dimension), such as: (1) characteristics; (2) influence on technology development; (3) factors associated with the respective category (proximity); and (4) measurement indicators.

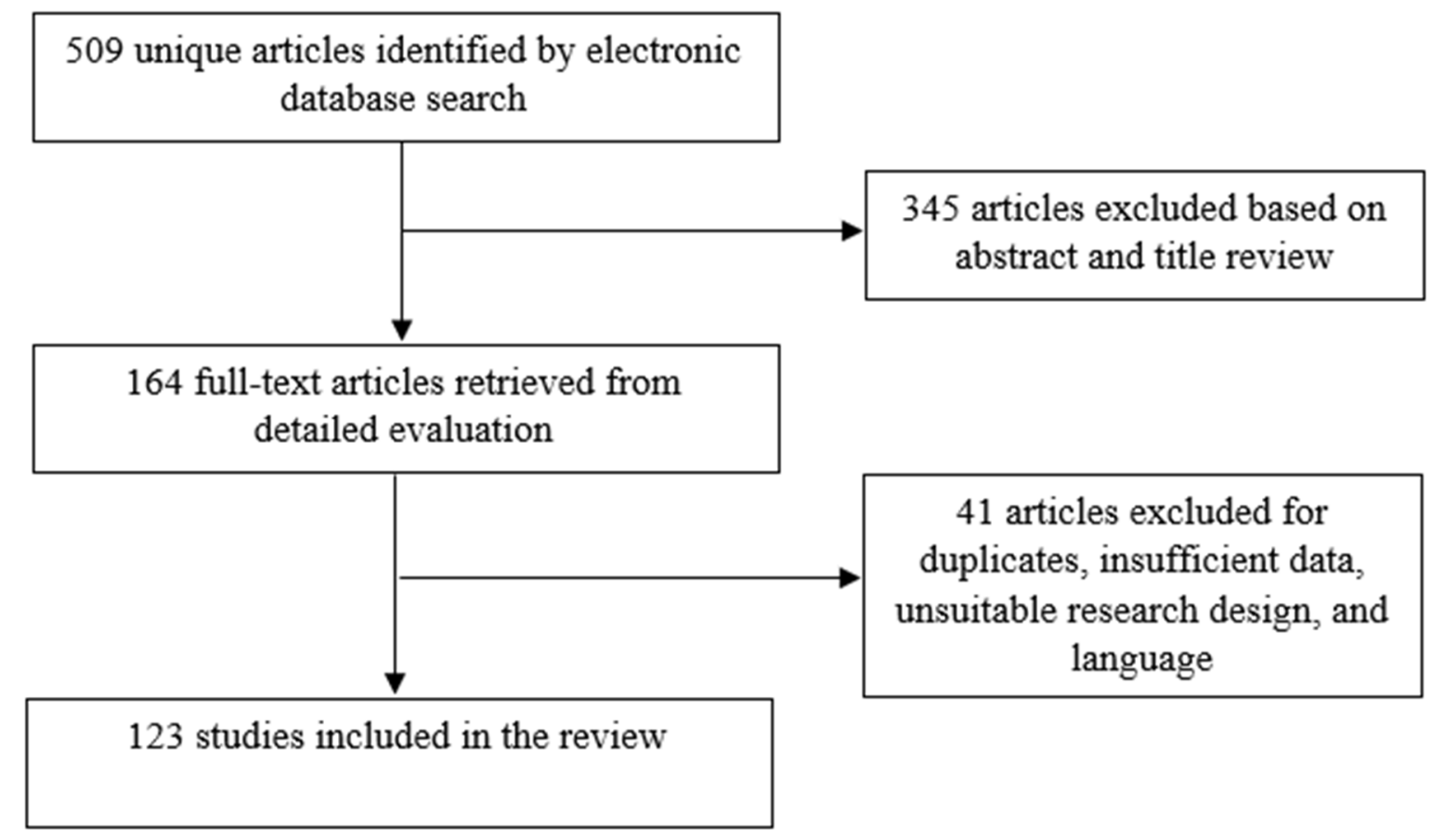

Figure 1. The literature review criteria flow.

\section{Results of Reviewed Literature}

The current study is based on review of 123 scholarly articles focused on the roles and measurements of proximity in sustained technology development. This section presents the results of the review of scholarly articles.

\subsection{Geographical Proximity}

Geographical proximity refers to spatial distance that influences face-to-face interactions and knowledge sharing, where closer agents are more likely to interact. Larger geographical distance between two or more partners make it difficult for knowledge transfer, especially with tacit knowledge $[12,18]$ because experiences and tacit knowledge can be concentrated in specific locations with low mobility and requires networks [19]. Geographical proximity influences knowledge transfer and learning but mostly strengthens other dimensions of proximity indirectly [15]. Geographical 
distance involves trade-offs between geographical and institutional proximities, such that collaboration between institutions is likely over short distances because similar geographical conditions (such as labor, funds, interpersonal factors) eases difficulties with institutional distance [20]. Their study also showed geographical distance positively influences mutual trust between partners, through face-to-face collaboration, and likely overcomes institutional distance.

Travel time is a good predictor of subjective distance than spatial distance, because people rely on distance to assess costs of travel to different locations and to make decisions about where to go [17]. Distance is significantly less important than time in explaining spatial-geographical behavior, and travel time is a measure of geographical distance, particularly in urban regions [17]. In other words, for travelers, time distance is more important than real physical distance, getting to target points depends on traffic intensity than on spatial factors [17,21]. Recently, information technology makes it possible to see and hear another person over distance. With technology, geographical distance ceases to be an obstacle to interaction which has created a borderless society [22,23]. Technologies helps overcome the information tower of babel that exists in businesses, and technology will enable the age of spreading knowledge that supports a borderless world of global citizenship [22]. This has significant implication for work practice as it affects how virtual teams work when dispersed in space. Teams can be present in time but in different places simultaneously but unless managed, information technology can destabilize relationship between organizations and employees when it comes to transfer of knowledge [24].

It has been demonstrated that previous collaboration, adequate technological similarities, and geographical nearness (relatively shorter travel distance between partners) positively affects innovative outcomes [27]. The experiences from prior collaboration initiatives enhance innovative outcomes of existing R\&D collaboration from higher perception of cooperation value, less likelihood of conflicts between team members, established collaboration practices and mutual trust [27]. Therefore, geographical proximity, prior ties, similar capabilities, personal relationships, and reputation of collaborative institutions influence collaborative innovation outcome.

The literature on geographical proximity shows that increase in proportion of local citations by inventors, contemporary knowledge production and economic development is encouraged locally within regions where knowledge externalities are created [28]. Although geographical distance influences innovative outcomes, there are threshold values after which the cost of collaboration rises and tacit knowledge remains geographically bounded in relation to codified knowledge [28]. Codified knowledge can be conveyed remotely but geographical limitation of specialized tacit knowledge influences density of technological innovation, regular face-to face interactions between partners and diffusion of tacit knowledge at relatively lower marginal costs [28]. A study of network relations on the Surrey science park shows relations between firms and university located within the science park is important for research activities however, intensity of university-firm interaction appears relatively weak [29]. Geographical proximity between actors within the science park promotes informal and human resources links but does not promote formal R\&D connection among companies and university. The informal links are sources of knowledge and information than formalized links [29].

Research has shown that distance does not hinder knowledge flow; geographical proximity is not an absolute precondition for knowledge transfer and network embeddedness [30]. The time co-locating does not necessarily generate new and productive knowledge, innovation output of a region cannot be forecasted based on regional innovative activities alone but the extent to which regional actors draw on external sources of knowledge significantly influences effectiveness of knowledge flow. The advantages provided by geographical proximity can also be provided by other means of proximity and technology increases likelihood of remote coordination, insofar technology is able to convert tacit knowledge into codified knowledge [31]. In particular, task clarity with central coordination tendencies allows tacit knowledge to be transmitted through large distance by other forms of proximity, where there are similar experiences [31]. For sharing of common codes and practices of communication that are tacit, face-to-face relations and geographical proximity are relevant for such activities. Therefore, 
geographical proximity can be substituted by other forms of proximity such as organizational proximity based on collective rules and organizational representations [32].

Referring to geographical proximity, borrower observed characteristics, risk and transparency of borrower influences collateral asked for by the lenders or bank, such that distance between lenders and borrower affects use of collateral, and distance provides information advantage that local banks have over distant banks [33]. Banks (lenders) closer to borrowers increase willingness of risk-taking such that physical proximity (or distance) determines collateral demanded because lenders require more collateral from local borrowers, and less collateral from distant borrowers as mechanisms for strict credit screening activities is implemented while lending to distant borrowers reduce incidence of collateral.

Overly proximate actors experience decline in information and knowledge exchanges after repeated interactions, called proximity paradox, because excessive proximity leads to narrow focus on particular technological activities and market behaviors to the extent partners become locked into sub-optimal habits which affects flexibility towards fast and external impulses [34]. The evidence suggests collaboration with geographically distant partners provide access to heterogeneous set of resources, which increase opportunities to develop new knowledge (re)combinations and reduces risk of relational inertia and cognitive lock-in associated with group ties between partners [26]. Therefore, there is a need for optimal distance between actors by maintaining high proximity in particular dimensions compensated by distance in other dimensions [34], as too much proximity can hinder innovation [15]. The physical location of firms co-located matters but so does quality of invested resources within geographical environment.

\section{Measurements for Geographical Proximity}

In analysis of co-publications, Ponds, Van Oort [20] used publication data from Web of science on disciplines that contributed most to science-based technological innovation. This method compared proportion of citations to scientific articles for different patent classes by estimating science-based technologies that linked science to technologies. Along 8 technological fields, indicators include author affiliation where single authors with more than one affiliation is considered to be collaboration, whereas multi-authored publication with one address does not count as collaboration [20]. The measurements for collaboration on spatial scale include addresses of organizations involved in publications collaboration at NUTS3 regional level that comprises cities and municipalities, and international levels which comprises European Union (EU) countries, USA, and other countries, to compare different areas of science related technologies (such as life sciences and physical sciences) [20]. The measurement focuses on types of collaboration and distance (travel time) between regions where collaborating organizations are located.

Spatial effects can be measured using three indicators as follows [35]. The first is physical distance between pairs, expressed in kilometers by road. A negative sign of coefficient indicates technological proximity in partnership decisions. The second variable is location of countries that pairs belong. This variable is assigned the value of 1 when pairs, $i$ and $j$ belong to neighboring countries. The third variable measures possibility to form connection when pairs belong to core of Europe or to periphery. A positive sign indicates collaborative network reinforces core-periphery structure, whereas a negative sign indicates partnership is beneficial to periphery countries in terms of competence development.

Using patent data with information on inventors, citation records, addresses of inventors and assignees, city, and state of inventors, Sonn and Storper [28] used addresses to assign US inventors to particular metropolitan areas, by zip list and methods that connects zip codes to cities and countries for geocoding at metro levels. When $N$ inventors are involved in a patent, each inventor is assigned a $1 / N$ portion of that patent, where citation between a cited patent with $\mathrm{N} 1$ inventor and a citing patent with N2 inventor was considered a collection of N2 citations to carry a weight 1/(N1N2). These fraction counts were summed for citing and cited patents that belonged to same geographical unit or total local citation (TLC) which is divided by total number of citations to derive total local citations percentage 
(TLCP) [28]. Self-citations are excluded, and localized citations and patenting activities are considered knowledge flow localization, which is then employed with Jaffe, Trajtenberg and Henderson's control technique (the JTH control technique) to construct control variables that connects each patent with control patent from the same patent class, application year, and closest grant patent date to the citing patents. The frequency of coincidence between number of cases where geographical location of a citation and the control patent (JTH control-matching frequency-JTHCMP) is used as proxy for distribution of knowledge-production activities. The net local citation percentage (NLCP) is calculated as: NLCP $=$ TLCP - JTHCMP. An increase in TLCP indicates increasing propensity to cite locally which also would increase NLCP. A decrease in JTHCMP indicates knowledge diffusion activities would increase opportunities for non-local citations [28]. If NLCP $>0$, then it indicates disproportionate citation of past patents by local inventors from similar geographical units. If $\mathrm{NLCP}<0$, then localized knowledge diffusion are not important. Therefore, NLCP over time is used to measure whether localization effects on knowledge diffusion is stronger or weaker.

The analysis in Gallié [30] measured spatial dimension using number of collaborations between each departments and partners in terms of location of each actor as differentiation factors. The main variables used to measure spatial dimensions are: (1) internal cooperation inside the firm; (2) Collaboration with partners located in bordering departments; (3) Collaboration with other departments; (4) Collaboration with the EU members; (5) Collaboration with the USA; and (6) Collaboration with other countries.

Geographical distance was measured using the following indicators. First, number of border crossing required to get from one region to another (geographical distance using contiguities matrix), and second distance in terms of duration of train journeys between regional capitals. Measurement indicator for distance (between regions) used dummy variable for intra-regional cooperation to determine co-location effects of pairs within same region and sectoral proximity index to measure sectoral profile between any two regions, based on Aquino Index (a value close to 1 indicates geographical distance, and 0 otherwise) [36]. In addition, a different measurement indicator for geographical proximity is a log transformation of spatial distance expressed in kilometers between universities and firms jointly developing patents [27]. Using information from Web of Science, Cunningham and Werker [37] measured geographical proximity in two ways. First, using geo-location of each organization in terms of longitude and latitude from Google Earth. Second, using relations between each organization to three levels of Nomenclature of Territorial Units for Statistics (NUTS): NUTS1 (main socio-economic regions), NUTS2 (disaggregated units for implementing specific regional measures), and NUTS3 (small regions used for specific diagnosis).

Similarly, geographical proximity has been measured according to co-location in similar spatial area, using information provided by Global Navigation Satellite System (GNSS) Supervisory database, and postal addresses from website of organizations and projects [38]. To determine degree of geographical proximity, information retrieved was classified into three spatial areas using NUTS9 classification (same country, same NUTS-1, and same NUTS-2).

Geographical proximity was measured using spatial separation between a firm and main partners in terms of: ultra-local (less than $5 \mathrm{~km}$ ), local (5 to $50 \mathrm{~km}$ ), regional (50 to $250 \mathrm{~km}$ ), national (more than 250 km, but in France) and international (outside French borders) [39]. Similarly, spatial effect was measured using the following indicators [40]. First, variable $\mathrm{d}_{\mathrm{ij}}^{1}$ that indicates geographical distance between two regions $i$ and $j$ according to great-circle distance between economic centers of regions, and second, dummy variable $\mathrm{d}_{\mathrm{ij}}^{2}$ that controls for neighboring effects (based on shared borders). The value of 1 is assigned when two firms are in the same region, which represents geographical proximity, and value of 0 otherwise. Likewise, geographical proximity has been measured according to cities that actors work, calculated using distance between cities in terms of great-circle distances (shortest possible distance between two spheres), latitude and longitude of respective cities [41]. Where geodesic distance refers to shortest path between two locations from respondent firms to relations firms. It has been shown that spatial proximity can be measured as inverse of linear distance 
between geo-located country's Travel to Work Areas (TTWAs) where each inventor is located [42]. TTWA is a dummy set to one if a pair is in same TTWA, whereas TTWA value is set to zero for inventors located in a different country. Correspondingly, geographical proximity has been analyzed according to co-location of actors, using proxy of co-location in municipality, co-location in region, and co-location in country [43].

\subsection{Cognitive Proximity}

Knowledge spillover and innovation are not intrinsic to spatially proximate firms [44]. Geographical proximity must be understood through different knowledge bases, as codified knowledge, limited face-to-face interaction and collaboration with global individuals and institutions are important for creation of knowledge and innovation activities [3]. The extent that firms can acquire knowledge generated elsewhere depends on openness to external knowledge and cognitive space $[10,45]$. Cognitive proximity refers to partner's similarity in terms of experiences and expertise in specific knowledge fields [10,12]. Cognitive proximity relates to intellectual alignment between actors that measures familiarity with newly searched knowledge in relation to firms existing knowledge base (including absorptive capacity and receptivity). To access and understand knowledge that actors contribute to innovation and technology development, cognitive proximity allows for searches on knowledge relatedness and resources to recombine valuable knowledge [10,46-48]. Sharing related expertise and experiences in knowledge area enhances mutual understanding and allows partners to communicate easily as they share similar knowledgebase [49]. Adequate cognitive proximity provides balance in incentive structures between academic and non-academic knowledge where there are conflicting interests (or goals) between academia and industry collaboration [20].

Collaboration diversity positively affects innovation projects when partners share basic knowledge [27]. The role of networks show that in-depth knowledge can only be generated through networks of relationships with knowledgeable partners, and these networks establish links among individuals and within markets to businesses, institutions, and organizations [50]. Sustained innovation cannot occur without deliberate continuous learning activities that affects ability for a firm to employ knowledge assets, as well as innovation culture expressed through investment in valuable capabilities and stakeholder integration for competitiveness [51]. Similarly, learning and knowledge management significantly influenced sustained innovation which indirectly influenced organizational performance [52]. It has been shown that inter-firm network is a valuable resource that enhances firm's performance and provides new knowledge that complement actors' absorptive capacities and develops trust [53]. As resources are scarce, it is firms with valuable resources to offer, such as products, services, knowledge, and access to technologies, that can easily attract qualified partners in networks [50]. Network capabilities can provide competitive advantage only when a firm is able to apply available technologies by inter-organizational relationships, that requires investments in network competencies [54]. Competitive advantage is sustained through interaction effects between internal capabilities within firms, and common capabilities of networks, which underscores network management for optimal results [55]. A firm's position within network structure determines resources available in absorbing new knowledge [53]. The knowledge flows in dense network (where there is knowledge familiarity) hinders novelty, but as cognitive distance increases, absorptive capacity decreases and there is consequent increase in novelty value which explains inverted-U shaped relationship between cognitive distance and innovation [46,53]. Structural holes, gaps in information flows created when two unrelated firms linked are similar firms but not to each other [56], influences a firm's innovative performance by bridging its to access diverse and novel knowledge and information that can be beneficial to firms [53]. The term network competence refers to a firm's ability to manage relations with partners and other actors within a network, which must be nurtured and managed as they can erode over time [54]. Network competence can be deployed at different levels to manage business relationships with other similar actors and portfolios (the net of business relationships that comprises entire business relationships of a firm) [57]. Research suggests that collaboration experience 
improves subsequent collaboration performance, but for a firm to succeed in collaboration it requires network capability to manage multiple relationships with actors through appropriate mechanisms, routines and making changes in collaboration relationships when required [58]. In addition, firms must master four levels of complexities in managing business networks and relationship to successfully compete in modern network environment [50]. These four levels include: (1) industries as networks that focuses on network visioning, (2) firms in a network that focuses net management, (3) relationship portfolios that focuses on portfolio management, and (4) exchange relationships that focuses on relationship management.

However, cognitive distance (far, but not too far) between firms is important for the following reasons [10]: First knowledge creation requires different complementary types of knowledge, which includes newness of sources that can generate novel ideas and creativity. Secondly, cognitive proximity can lead to cognitive lock-in $[10,59,60]$ where practices within firms hinder views on innovation, novel technologies, or new market potentials. Thirdly, cognitive proximity raises risk of involuntary knowledge spillover where it is impossible to prevent knowledge that spills over between organization which can produce unwanted benefits for competitors to exploit [10]. Therefore, actors need to have cognitive overlap that is sufficient to allow for knowledge transfer, communication, and knowledge absorption, but not too much cognitive proximity to allow for lock-in effects [61].

Several empirical studies have showed that cognitive proximity provides technological advantages for a firm's competitive performance (sustainable technology development). In a study of 18 pharmaceutical firms involved in 571 R\&D arrangements, Wuyts, Colombo [46] found that technological innovation occurs at intermediate levels of partner dispersion with firms that maintain balance between R\&D partnership, and avoids narrowness lock-in. Similarly, it has been shown that information asymmetries are lower for firms that are technologically related, and technologically proximate firms are preferred targets for mergers and acquisitions because technological relatedness, proximity, complementarity and ex-ante knowledge flows enhances firm merger and acquisition benefits, especially for small and medium-sized enterprises (SMEs) as attractive forms of non-organic growth strategies to gain access to knowledge and technology [62]. Research findings indicate that cognitive proximity improves knowledge spillover for regional economy, enhances mutual learning through absorptive capacity, when there is cognitive distance, that enhances possibility for innovation novelty [60]. Cognitively proximate partners in less complex knowledge environment can engage in knowledge transfer and knowledge translation directly than cognitively distant partners in complex environment where knowledge brokers must translate knowledge to make it comprehensible. The influence of cognitive proximity depends on optimal cognitive distance that is the point where actors are satisfactorily distant for novelty to occur, but close enough such that cognitive distance does not hinder knowledge exploration $[60,63]$. Research suggests that firms develop specific path of technical knowledge buildup through technology alliance where firms can rapidly convert technological resources and capabilities into core capabilities [64]. This is supported by findings that cognitive proximity has positive effect on hard outcomes (innovations, publications, and financial turnover) and soft outcomes (shared knowledge, collaboration programs, and support for ideas) [41].

\section{Measurements for Cognitive Proximity}

Patent data citations has been used as proxy for knowledge spillovers between different industries using un-centered correlation for technological distance between two firms within same technological space based on particular technological International Patent Classification (IPC) class [65]. The firm's technological space is the angular intersection that represent technology closeness and spillover industries closely related by shared or similar processes. If two firms share patent activities, then technological relatedness will be equal to 1 , otherwise 0 . In this sense, technological distance is measured as distance between two firms' portfolios of technologies based on frequency matrix of two technology classes collectively assigned to similar patents for a particular firm. Similarly, cognitive distance has been analyzed using patent portfolio vector to identify proximity between firms within 
particular knowledge space [66]. The distribution of patents across different classes characterize firm location in terms of knowledge space, and cognitive distance between firms is represented by distance between vectors of patent class listings. Along similar lines, Euclidean distance was used to represent dissimilarity between two industries, where higher value of Euclidean distance indicates low technological and cognitive relatedness compared to different firms, and low value indicates knowledge in particular patent class is less likely to be collectively used for innovation [67]. Correspondingly, cognitive distance has been measured by distance between two patents and outlier patents, first creating binary technology vector for different technology positions with mainline subclasses for each patent [68]. This approach uses technological components of two innovations within same industry but with different technologies for technological relatedness, technological footprints of different firms and similarities and differences between technologies of different firms. Patents that describe technological fields provide opportunities for incremental innovation, while patents that describe distant technological fields or combinations that are more unusual suggests radical innovations. Technology map (proximity or distance between different knowledge areas based on patent classification) can be used to measure cognitive distance between technological fields according to co-occurrence IPC classes such that related but diversified innovation represents close technological distance to diverse knowledge base, and unrelated but diversified innovation represents remote distance to knowledge base [69]. The classification assigned to patents within a knowledge area together with patent class in another area indicate short technological distance between technological areas within patent classes [69]. Using regional patent data from European Patent Office (EPO), Barber and Scherngell [40] measured cognitive distance as a vector of firms' patent share in each technological subclass (based on third-digit level) of IPC class. Technological proximity is calculated using Pearson correlation coefficient between technological vectors of two regions of pairs. Likewise, research has shown that cognitive distance can be measured using joint patents by different universities in EU in terms of overall number of registered patents at EPO between 1998 and 2003 using un-centered correlation [27]. The priorities between universities and firms were measured as binary value where value of 1 is assigned to previously registered joint patenting at EPO, otherwise a value of 0 is assigned. In addition, cognitive distance of a firm relative to other firms was measured using revealed technological advantage (RTA) index to measure technological convergence, where a positive RTA value indicate relative specialization in a patent class, and positive correlation of RTA indicates smaller technological distance, otherwise larger technological distance [53]. In contrast, variables that rely on financial metrics have been used to measure cognitive distance [35], namely: number of projects submitted by each pair, average cost of project submitted by pairs, and share of financial support by pairs. Positive values for these measures indicate technological closeness, whereas a negative sign suggest technological gap.

In contrast, the following indicators have been used to measure cognitive proximity. Degree of difference in technical terms by actors, degree of difference in specialized instruments, software, machines used by actors, degree of difference in technological expertise between actors, common activity that indicates similarity in daily activity (such as management, policy making, research, maintenance, and operations) between actors [41]. Additional measurement indicators include value of knowledge exchanged in terms of problem solving, type of knowledge exchanged (technological knowledge and non-technological knowledge), type of organizations involved in knowledge exchange, duration of collaboration, and presence of social base underlying knowledge exchange in terms of common background such as former colleagues or classmates [70]. Correspondingly, cognitive proximity has been measured using common technical language, similar technology or product, similar work-related technical details, and similar work-related expertise [71]. Likewise, cognitive proximity was measured using compatibility of technological equipment, common language, common code, or common culture [39], as well as proximity in terms of firms' product or process characteristics [72]. Furthermore, it has been shown that cognitive proximity can be measured based on characteristics of a firm according to four core competencies: infrastructure, hardware, software, services components. 
These indicators are assigned value of 1 for cognitive proximity, otherwise 0 [38]. In contrast, research findings indicate that cognitive proximity can be measures based on technological research profile of each organization in terms of major nanotechnology (product) categories. The larger overlap between two organizations in technological research profile, the closer they are technologically [37]. There is evidence that cognitive proximity can be measured according to scientific domain of actors such as environmental, Chemistry, Conservation, Diagnostic, Physics, Information and communications technology (ICT), Optoelectronics, Restoration and Visual 3d. Consequently, actors that belong to similar scientific domain are cognitively proximate, otherwise not [43].

\subsection{Organizational Proximity}

Most organizations have deeply rooted routines and incentive where organizations with similar structures and incentives are more likely to interact with similar other organizations [73]. Partners that are organizationally proximate identify with synergies that facilitates smooth collaboration [74]. These partners consider themselves fit in certain ways that allows them to collaborate effectively and have developed relationships through previous collaboration within similar groups, or based on long-term contract affiliation $[38,75,76]$.

Organizational proximity is the extent that relations are shared in organizational arrangement between or within organizations, based on autonomy and control such that high level of control to regulate organizational interactions reflects high organizational proximity [10]. On the other hand, high autonomy within and between organizations reflects low organizational proximity. It has been argued that organizational proximity controls knowledge diffusion (for example, ownership of intellectual property rights directs technology development) and decreases transaction cost, but can hinder interactive learning, limit flexibility because organizational actors become path dependent and over reliant on other actors [10]. Organizational proximity includes dyadic and structural levels that characterize relationship between actors. The dyadic aspect focuses on organizational proximity determined by similarity in firms background where different partners operate whereas structural aspect of organizational proximity looks whether firms belong to similar network and examines network characteristics [12]. The organizational network involves large number of different participants that connects partners, joint ventures, and links partners in strategic alliances with suppliers, service providers and contractors [77], based on complexity of transaction, capabilities of value chain and knowledge potential [78]. Through organizational proximity members of organizations as well as actors develop collective framework for communication and coordination [79] to improve collaboration with ease of information and knowledge combination [12] for partners to work towards complementary objectives, subject to similar institutions, structure, or cultures [80].

It has been found that universities used organizational, geographical, and technological proximity for exploitative relationships (relationships that applies existing technologies), but distant technological competences for explorative relationships (relationships that pushes boundaries of existing technologies or innovations) [74]. In analyzing proximity across nations, using affiliation between patent applications and inventors of patent to similar firm, it has been shown that bilateral collaboration is positive when there is common language, common border, and similar cultural characteristics [81].

In one study, on proximity and collaboration in European nanotechnology, Cunningham and Werker [37] found that organization types differ in ways they uptake new knowledge. For example, academic organizations are successfully able to broker relationships on wider range of potential topics whereas non-academic organizations are more productive and more specialized in technological and collaborative interactions [37]. Although organizational proximity does not directly influence collaboration, it does have indirect effect such that academic collaborators are more able to mediate technological distance with higher overall mediation productivity, which is different than non-academic organizations with higher marginal productivity for relatively proximal technological partners [37]. 
It has been found that rich network of interpersonal relationships in organizational proximity for firms belonging to similar business groups can reduce obstacle to knowledge sharing and reduces threat of opportunism that affect alliances between spatially distant firms [26]. Geographic distance and organizational proximity are contingent upon one another in effect on innovative performance of knowledge-creating alliances and distance (proximity) in one dimension can be bridged by proximity (distance) in another dimension [26].

\section{Measurements for Organizational Proximity}

Organizational distance has been measured using physical distance in kilometers $(\mathrm{km})$ between locations of a bank's headquarters and capital of province where a firm is located such that bank-firm organizational distance was measured using inverse of distance [33]. Similarly, organizational distance has been measured using distance in kilometer between province of firm and bank headquarters [82]. In contrast, it has been shown that organizational distance can be measured based on whether two organizations belong to same corporate group, such that a binary variable is assigned the value 1 when two firms are owned by same corporate group, or 0 otherwise [38]. Along similar lines, organizational proximity has been measured according to sectors such as academic or non-academic character, where cross collaborations between organizations with different backgrounds show high organizational distance [37]. A different measurement indicator for organizational proximity is based on procedures and routine of organizations that includes the following proxies. OP-Adapt: measures degree of difference between a firm and partner in adapting to new circumstances. OP-Management: measured difference between a firm and partner in adhering to strict planning and financial management. OP-External: measures degree of difference between a firm and partners in freedom to initiate relations outside respective organizations. OP-Procedures: measures degree of differences between a firm and a partner in preferring to stick to procedures to achieving results. OP-IP: measures degree of difference between firm and partner in protecting intellectual property [41].

Organizational proximity can be measured using patent related information that measures organizational proximity using dummy variable assigned the value 1 if two firms share similar inventor applicant and 0 otherwise [42]. The scaled organizational proximity is calculated as a dummy variable, which takes the value 0 if applicants are different; the variable is assigned 1 if applicants are same or there is more than one applicant and assigned 2 if applicant is same and there is only one applicant on the patent. Similarly, temporary project organization has been used as proxy to measure organizational proximity by year of collaborations between two actors that work together for some years to develop organizational routines that help them work together [43]. Likewise, organizational proximity has been measured using convergent methods of organization between firm and partners [39].

\subsection{Social Proximity}

Social proximity refers to relations between actors embedded in social context based on trust, friendship, similar experiences, shared rules, and network ties that facilitates exchange of knowledge $[10,49,83-85]$. Socially proximate partners are likely to trust one another and less likely to express opportunistic tendencies towards one another [49]. Trust, in this sense, refers to the level at which people will not be opportunistic unless temptation exceeds resistance threshold which depends on values and norms, experience, character, kinships and friendship [61]. However, excessive social proximity can lead to over-reliance on social relationship for knowledge and information which can hinder innovative performance and can lead to opportunistic behaviors that undermines projects [10]. Social embeddedness is associated with trust and functions as control mechanism against opportunistic behavior particularly when innovation involves tacit knowledge, trust may be important coordination mechanism but when knowledge can be codified trust can also be formulated in contracts, and interpersonal trust is then of lesser importance [86]. The concept of social proximity overlaps with social and structural embeddedness, influences of shared social space on innovation and learning at micro level to facilitate knowledge transfer and achieve common outcomes [12]. Trust-based ties 
facilitates knowledge transfer and learning process; therefore, degree of social embeddedness is important to understand economic outcomes [87].

In analyzing economic contribution of skilled immigrants (Chinese and Indians) as entrepreneurs and indirect facilitators of trade and investments in countries of origin, it has been found that reciprocity as well as trust in ethnic communities enable knowledge exchange among members of migrant communities in Silicon Valley that facilitated outsourcing of software development from host countries to home countries [88].

It has been shown that knowledge spillover arises from social network developed through interactions and mutual trusts among firms and individuals [89]. That is to say, social connectedness based on personal acquaintances or common working experiences between firms and individuals played more important role in knowledge spillover. Therefore, knowledge is not readily accessible to all actors in network locality but rather developed through particular channels between connected individuals. Building and maintaining trust is an important aspect of network competence, which can also be attained through previous collaboration experience [57].

There is more benefit of geographical (spatial) proximity for socially distant firms, and more benefit for firms in similar technical community of practice (social proximity) even when not geographically proximate [90]. Therefore, social connections more likely resist geographical distance because knowledge diffusion follows interpersonal channels such as co-ethnicity, friendship, acquaintances, and labor mobility [91]. Therefore, geographical and social proximity are substitutes in terms of influence on access to knowledge [90].

\section{Measurements for Social Proximity}

Social proximity has been measured using patent information (names, surname, addresses and company affiliation of each inventor and patent documents) to indicate type of linkages from participation with common team of inventors, mapped to a bipartite graph (a graph that describes connections between two distinct groups) which measures distance among pairs of inventors in network by geodesic distance of degree of linkages by cited patents and other citations, where missing linkages suggest actors are not connected, whereas linkages (direct, indirect, and perfect) between two patents indicate connection [92].

Similarly, other measurement indicators for social proximity are based on network connection [35] as follows. The first measurement indicator is network position of partners in prior period in terms of direct and indirect partners of each individual. This measure includes number of common projects that pairs financed within European Commission $5^{\text {th }}$ Framework program (previous period). The second measure of social proximity indicates minimal number of connections, geodesic distance, between pairs in prior network where the variable is assigned 1 for firms involved in same project, which shows social proximity, and 0 , represents no connection between firms. The second measure of social proximity is number of connections between pairs. Firms are connected if they jointly submitted a proposal to the European Commission in the 6th Framework program [35]. This was measured using a binary variable that is assigned value of 1 when pairs jointly submitted a proposal, and 0 otherwise.

As social proximity evolves each year, measurement indicators use three matrices of geodesic distance of 2 (the partner of a firm's partner) to test whether partners of partners who share social proximity in a particular year $(t)$, are likely to collaborate subsequently in another year $(t+1)$ [38]. At distance 2, number of actors with indirect connection between actors, such that few indirect connections between actors indicate stronger tendency for network closure. Stronger network closure arises from less geodesic distance equal to 2 [93].

In contrast, measurement indicators based on interpersonal factors [71], include: (1) Knowing each other: degree to which individuals know each other in terms of private life based on prior interactions. (2) Emotional Closeness: extent of emotional closeness that individuals feel in the contact in terms of caring about personal wellbeing. (3) Feeling of personal obligation: how much one feels 
personally obliged to help a contact if the contact asks for help, but it would require a significant amount of time [71].

In a similar way, there are measurement indicators based on repeated collaboration, trusts, nature of relationship using the following proxy [41]. The main group includes SP-Effort, SP-Trust and SP-Share. SP-Effort refers to willingness for a firm to put effort into doing what a partner requests. SP-Trust refers to trust that a firm has in contribution to partners. SP-Share refers to willingness for a firm to share information with partners. In addition, other variables include the following. Gender similarity and age difference between actors. Time: how long the alliance partners have known each other. Frequency: the frequency that alliance partners meet each other. Private: whether a firm and its partner have non-business relations. Same Soc. Sector measures whether a firm and partners belong to same societal sector such as business, government, academia, NGO.

Comparably, social proximity is measured in terms of previous co-inventions of actors, co-authors in common and indirect links to actual or potential partners, using steps between inventors to measure social distance such that if pairs have co-invented previously then number of steps between them is 0 . If pairs have not collaborated directly, but have both worked with $k$, then there is one step between them; if $i$ is connected to $j$ through $k$ and $L$, there are two steps between them [42].

\subsection{Institutional Proximity}

Institutional proximity refers to controls designed to organize political, social, and economic interaction [94] through shared values, norms [10], common social subsystems [20] rules and regulation to reduce uncertainty, lower transaction costs, facilitate interaction and knowledge exchange [84]. Institutional proximity refers to factors, such as laws, rules, norms, and value, that provide favorable conditions for knowledge exchange, interaction $[10,13]$ and stability for cooperative behavior among actors [95]. Three dimensions characterize institutional systems in terms of proximity: regulatory, normative, and cognitive [96] which determines how individuals within society identify and interpret reality. First, regulatory dimension refers to rules and regulation of a region monitored and enforced using sanctions and punishments to deter and regulate particular behaviors. Second, normative dimension focuses on norms, values, and beliefs, morally governed to promote anticipated goals and behavior within particular national environment to enhance legitimacy by compliance with socially constructed guidelines. Third, cognitive dimension refers to cognitive structures, shared knowledge, and ways society uses cognitive elements. The normative and cognitive aspects of institutional distance correspond with North [94] conception of informal institutions that can be broadly categorized as cultural institutions. On the other hand, formal institutions are represented in codified laws, rules, and regulations, while informal institutions are structurally constructed, can be non-codified practices, values, and norms [96,97]. Therefore, firms depend on formal and informal institutions to understand and respond suitably in existing and potential markets [97].

Countries have different national institutional environments and business practices that influences foreign organizations that operate within host countries [98,99]. Institutional proximity facilitates interaction over cross-national distances, large institutional distance between foreign affiliate and domestic firms reduces ability of domestic firm to access knowledge spillover by foreign affiliate [100]. Spatial and institutional distance imply a trade-off between two types of distance (geographical and institutional) [20], as actors from different location find it difficult to collaborate because rules or legislations are different. In one study, that analyzed Chinese patents from 1985 to 2004, in terms of formal university-industry collaboration in China, it has been shown that while geographical distance hinders collaboration, institutional proximities reduces negative effects, especially when geographical distance increases [101]. In addition, collaboration between firms that are institutionally distant makes for difficult contract codification which gives rise to dependence on less formal institutions to avoid conflict of interest or opportunism [20]. Other studies have reported that certain institutional systems can lead to institutional inertia that hinders interactive learning and institutional reforms [10]. For example, academia, government, industries operate under institutional 
regimes that have different incentive and goals that can be incompatible and lead to conflicting issues [102]. Institutional distance increases liability of foreignness faced by foreign firms through discriminatory, relational and unfamiliarity hazards that imposes adaptation burdens by foreign firms within host country [103], that would otherwise not be incurred by local firms [104]. Discriminatory hazards are unequal biased treatments imposed by government, consumers, and suppliers of host country on foreign firms $[103,105,106]$ which can discourage foreign firm entry and inhibits resource opportunities available to foreign firms within host country $[107,108]$. Common factors associated with discriminatory hazards include: legitimacy deficit [109], attitudes of openness towards foreign cultures, norm in host country, societal expectations, inclinations for foreign consumptions, and consumer ethnocentricity $[95,110]$. Relational hazards are challenges faced by foreign firms in terms of coordinating within a firm and components outside a firm that represents internal organization and external market transactions [103]. Relational hazard describes problems associated with managing relationships at a distance, and include challenges associated with: monitoring, dispute settlement, dissimilar cultural backgrounds [111], opportunistic behavior [112], and lack of trust in unfamiliar partners [113]. Unfamiliarity hazard are potential challenges associated with lack of knowledge of foreign markets, incurred to acquire information about operating environment within foreign markets. Foreign firms are at unfavorable position because they suffer from information asymmetries which arises from absence of information about host country market, language, norms, and politics [114]. As a result, foreign firms would have to incur potential start-up cost to obtain important information about host country market and competitive environment [103]. Sources of unfamiliarity hazard include: limited experience with foreign environment [115], insufficient information about host country [116], and lack of (or insufficient) actors in host country [117].

The institutional environment helps understand institutional structure and pressure that exists to develop market entry strategies to integrate into host country. Small regulative distance allows firms to adopt entry strategy of fully owned subsidiary or majority joint venture where regulative distance is higher and requires lower resource commitments, while smaller normative distance encourages high equity control over joint venture or low equity control where normative distance is higher [95]. Regulatory distance is an important aspect of international expansion strategy that sets rules and regulations required in host countries, which can also constrain firms' innovation activities [95].

Institutional distance has been measured in terms of ability for firms to transfer resources and practices between different contexts that facilitates market entry and legitimacy by foreign corporations in host countries [118]. For example, firms from developed countries seeking to enter developing country markets are faced with high institutional distance between host country and home countries as well as high institutional uncertainty in host country [118].

\section{Measurements for Institutional Proximity}

To attain proper operational legitimacy, organizations must respond to institutional expectations and values by integrating components of institution in policies, products, and practices to conform with socially legitimate norms that reduces institutional heterogeneity and provides social fit, a practice referred to as isomorphism [119]. Isomorphism enables an organization gain similarity in structure by conforming in practices and forms in a way to become similar, as well as compatible with environment to increase chances of survival $[120,121]$. Local isomorphism has been measured using models that compare assets strategy of foreign banks subsidiary with US banks within same local markets [122]. Assets portfolio of these banks were measured using defined assets classes for foreign bank subsidiary and all US commercial banks as a proportion of subsidiary total assets. Subsidiary assets of foreign banks were compared with average asset strategy of US banks metropolitan statistical area (MSA) which was used as area of interest. Based on local isomorphism strategy for foreign bank subsidiary, asset strategy portfolio is categorized according to Miller and Eden [123] eight categories (Anit: $n=1$, .. 8) of banks assets: commercial loans, real estate loans, loans to individuals, other loans and leases, cash, overnight money, securities, and fixed assets [122]. The mean of asset strategy for different 
MSA is then calculated. A larger value of local isomorphism strategy (LIS) indicates greater local isomorphism (a bank closely resembles domestic banks in local market for a particular year) [122]. Furthermore, institutional distance was measured using multidimensional approach including cultural distance (CD), economic distance (ED), regulatory distance (RD) and political distance (PD) [122]. CD between parent firms, home country and US was measured using power distance, uncertainty avoidance, individualism/collectivism, and masculinity / femininity. ED was measured using financial market orientation obtained from UN World development indicator database to measure economic distance using a ratio of market capitalization/GDP divided by bank credits to private sector/GDP. A higher value of ED shows high difference between home country's financial market and that of the US. RD was measured using international differences in regulations obtained from banking regulations database that compares regulations across countries. The authors used variable such as bank activity regulations, banking/commerce mixing regulations, competition regulations, and capital regulations dimensions to develop measures of regulatory distance. A high $\mathrm{RD}_{\mathrm{i}}$ indicates higher regulatory distance between the home country and the US. Salomon and $\mathrm{Wu}$ [122] measured political distance using CHECKS index (proxy for number of veto players in a political system, adjusting for political cohesiveness) obtained from Database of political institutions that represents number of veto players in political systems adjusted for political cohesiveness and indicated level of political volatility within a country. Political distance was measured as absolute value of difference between political volatility between foreign firm's home country and US. Higher value of PD indicated higher differences between political environment in home country and the US.

Institutional proximity is measured based on whether a firm has similar institutional form developed by Etzkowitz and Leydesdorff [124]: (1) Universities and public research centers; (2) Firms, (3) government; and (4) public. In other words, these measures are based on whether firms or actors belong to similar sectors [38]. In addition, quintuple helix model (comprising five helices: education system, economic system, natural environment, media, and culture-based public and political system) demonstrates how knowledge moves from different institutional subsystems in circular fashion to new innovation that addresses environmental and sustainability challenges [125]. The quintuple model takes environmental challenges into concerns and improves understanding on ways that application of knowledge, from five helices identified above, are transformed into sustained development.

In contrast, the following measurement indicators rely on spatial variables [40], namely: (1) Dummy variable $\mathrm{d}_{\mathrm{ij}}^{3}$, which is country border variable assigned the value of 0 when two regions are in same country, and 1 when two regions are located in different countries. (2) Language area dummy variable $\mathrm{d}_{\mathrm{ij}}^{4}$ that is set to value of 0 when two regions are in same language area, and 1 otherwise.

Additionally, there are measurement indicators that categorize actors based on: research centers, public institutions, small and large firms, and universities [43]. These classes define and measure organizations in terms of similar institutional forms. Correspondingly, other measurement indicators examine spatial elements of collaboration, and distinguish between types of organizations (academia, companies, governmental and non-governmental organizations) in terms of homogenous collaboration (between similar organizations) and heterogeneous collaboration (between different organizations) [20].

In summary, review conducted in the current study identifies the roles and measurement indicators for proximity. The main ideas identified in scholarly articles reviewed have been summarized in Tables A1 and A2 respectively (see Appendix A) to aid quick but detailed comprehension for managers, policy makers and researchers.

\section{Discussion}

The current study aimed to provide deeper understanding on proximities, and its influence on sustained innovation and technology development. This was achieved through a literature review that organized and synthesized 123 scholarly articles to answer the research questions. The main research question in the current study is to understand: what are the roles of proximities in sustainable technology development? We divide the main research question into the following sub-questions: 
- How were innovation proximities defined and measured in existing literature?

- What are the roles of proximities while developing innovation networks for sustained technology development?

\subsection{How Were Innovation Proximities Defined in Existing Literature?}

This question is not trivial as scholars have long debated significance of non-spatial factors for innovation and sustained technology development. It has been shown that there are at least five proximities (geographical, cognitive, organizational, social, and institutional) important for interaction with distant partners that are not co-located [3]. The main arguments from review synthesis is that sustainable technology development can occur regardless of territorial co-location which may deter technology development such as when neighbors ignore each other, compete, or refuse to cooperate [7]. A crucial finding from the review is that emphasis is not on spatial or non-spatial dichotomy, but on degree of similarities and dissimilarities of knowledge assets that can be used for innovation and sustained technology development. Therefore, there is merit to the argument that spatial dimensions significantly influence knowledge transfer for innovation $[4,5,8,126]$, but this perspective must be complemented and reconciled with evidence of significance of non-spatial proximities which highlights interpersonal factors as important components of sustained technology development.

\subsection{How Were Innovation Proximities Measured in Existing Literature?}

The issue of standardized innovation measurements is at the forefront of research. Scholars encourage use of measurement indicators that goes beyond traditional metrics when necessary, which is accessible and adaptable to stakeholders in variety of context [127].

Patent related information was commonly used to measure proximities, and the studies were all conducted in developed countries. This is clearly a research gap that could be filled by future studies, as many developing regions do not have structured patent data. For example, in a study on 65 low income countries, it has been found that only 17 essential medicine are patentable, but usually not patented, with overall patent incidence as low as 1.4 percent [128]. Similarly, it has been shown that national patenting on biotechnology was relatively low, while industrial patenting was limited in developing countries which limits ability of some developing countries to harness their inventions [129]. In addition, many developing countries do not have registered patents, and some fail to protect patents on products, which has stagnated access to products and served as disincentives to invest in such developing countries [130]. Part of the reason is relatively lower prices in developing countries deter or delay multinationals from entering such markets which implies loss of assess to patented products in developing countries [131]. Furthermore, intellectual property regime in some developing countries does not support objectives of innovation systems which creates social costs [132]. Research suggests that developed countries patent protection shares a positive relationship with changes in total factor productivity, whereas low income countries with less R\&D infrastructure have not emphasized strong patent protection [133].

Based on the findings, we discuss measurement indicators for proximities as follows. First, the review found that geographical proximity was commonly measured using nomenclature of territorial units for statistics information, which largely corresponds with municipality co-location, geodesic distance, great-circle distance, addresses of inventors and total local citations. A few studies used travel time (in kilometer) between actors to measure geographical proximity. Second, cognitive proximity was commonly measured using patent related information that was derived from electronic databases such as joint ownership, patent registered, joint project proposal, patent class information and patent subclasses. The findings showed that few studies measured cognitive proximity using similarity between actors in aspects such as shared jargon, similar knowledgebase or expertise and profile relatedness of actors. Third, common measurement indicators for organizational proximity include physical distance (in kilometers), shared patents ownership, similarity in firms parent structure, similarity in industry, and degree of flexibility of individuals and organization in routines and practices 
commonality. Fourth, social proximity was mostly measured using network connections as indices for co-patented activities between actors to measure type of connections, network positions, co-inventions, and sponsorship of registered invention. The findings showed that measurement indicators rely on survey data and non-patent related information as proxies for familiarity between actors, interpersonal supports, trust, and openness to share and support one another. Finally, review showed that institutional proximity was measured using structured country-level data on political, economic, and socio-cultural indicators for host country, as well as institution-based data such as similarity between actor industry.

The main challenge with existing measurement indicators emerges from less adaptability across different context. From the findings, we can infer that existing measurement approaches are suitable in developed countries where there are structured data, such as NUTS and patent data. However, the measurement indicators present challenges in developing countries where there are less structured data, which arises from economic and structural factors that can affect the extent that actors in developing countries are able to determine influences of proximities on sustained technology development. Therefore, existing measurement approaches are insufficient for such context which suggest a need for measurements that must reflect economic and structural challenges exemplified through robust, reliable, and flexible survey data to determine measurements for proximities, as well as to existing framework such as triple helix and quintuple helix to measure proximity.

\subsection{What Are the Roles of Proximities While Developing Innovation Networks for Sustained Technology Development?}

The findings show that proximities develop innovation networks that influence sustained technology development, discussed as follows.

Geographical proximity can be mostly suitable for transfer of tacit knowledge [12,18], as closer actors are more likely to interact face-to-face which eases knowledge transfer particularly on complex learning processes. In addition, geographical proximity enhances opportunity to develop mutual trust between partners [20] and builds informal link to resource assets that increases likelihood to collaborate for technology development. Although it was found that ICT can substitute for geographical proximity; however, the findings show this requires deliberate management to coordinate knowledge transfer and avoid knowledge related issues.

Considering the review, we infer that geographical proximity may be important but not sufficient for sustained technology development, and suggest the findings require careful interpretation as follows. Geographical proximity is mainly required for face-to-face interaction and transfer of tacit knowledge that is especially important for specialized firms to collaborate. Therefore, geographical proximity depends on the nature of knowledge transfer, such that codified knowledge may not require geographical proximity as much as tacit knowledge. However, the extent that geographical proximity can facilitate knowledge transfer depends on competence of knowledge management as well as availability of alternative mechanisms such as technology and ease of travel. Since geographical proximity is especially useful for transfer of tacit knowledge and face-to-face interaction, therefore geographical proximity can diminish overtime particularly when there is less need for tacit knowledge during innovation activities, in the sense that geographical proximity can be temporarily required for transfer of tacit knowledge. Furthermore, the need for optimal distance weakens the argument that geographical proximity is highly important for sustained technology development, as firms need to use new knowledge from divergent sources that may not necessarily be within clusters. Optimal geographical distance is particularly important to obtain new knowledge for innovation as well as to avoid lock-in, which can be useful for radical innovation. Physical interactions enabled by geographical proximity provides indirect benefits such that firms can identify and access pool of human resource talents. As individuals interact within similar regions, they may develop familiarity and mutual trust, as well as identify qualified potential employees or partners. As a result, geographical proximity is a strategy to complement and use locally available knowledge, whereas geographical distance can be 
used when required knowledge is not locally available. This provides convenient and cost-effective measures to use locally available knowledge assets. Therefore, geographical proximity can be described as a cost-efficient and convenient approach that uses and manages optimal spatial resources during required period of knowledge transfer to meet organizations innovation requirements.

The findings suggest that cognitive proximity has positive effect on innovation and knowledge sharing [41], as actors with similar knowledge base can interact easily with less communication barrier which facilitates smooth collaboration prospects [27]. Cognitive proximity allows firm to access and use knowledge from wide sources that is consistent with existing knowledge in terms of absorptive capacity that promote assimilation and recombination of sourced ideas for innovation benefits that can lead to radical and incremental innovation. Cognitive proximity relates to similarity in knowledge required to properly understand and transfer specialized knowledge assets that increases likelihood of knowledge diffusions between similar partners. Unlike geographical proximity where firms with resource capability can easily enter spatial regions, shared knowledge base for cognitive proximity can take years of training, education, and experience to develop which further reinforces capacity to learn more from similar other individuals. Also, cognitive proximity can be used regardless of spatial conditions. Therefore, cognitive proximity provides cost-effective alternative to geographical proximity, as individuals with similar skill do not have to be co-located within similar regions. However, cognitive proximity can harm innovation, as optimal cognitive distance is required for firms to obtain ideas and knowledge assets from external sources and then recombine with in-house capabilities to develop new technologies. Therefore, moderate cognitive proximity and distance deliberately managed to facilitate learning and innovation strategy of firms is required for sustained technology development. In other words, being too close may not produce new knowledge, being too far may produce knowledge that can be difficult to understand and make communication harder. Knowledge assets not properly managed for organizational benefits can bring about underuse, inefficiency and loss of intellectual property that can be used against a firm competitively. There is need to manage cognitive assets because transferred knowledge may present challenges as tacit knowledge can be difficult to apply throughout the firm. Therefore, knowledge must be managed and codified for transfer and use by the firm.

In terms of organizational proximity, the findings show that actors within same domain, with similar structure and incentives are more likely to collaborate as they share complementary objectives [80]. Also, this was shown to reduce bias of opportunism that can hinder collaboration [26]. In addition, Social proximity reflects interpersonal ties that is built on relatively higher trust which allows for knowledge transfer [10]. People within the same social ties are more likely to trust one another, which was shown to be particularly important for transfer of tacit knowledge, transfer of important valuable information and avoids opportunism through mutual trust. We found that social proximity withstands geographical proximity as knowledge transfer can occur through interpersonal ties from distance regardless of actors' physical location. Also, institutional proximity significantly influences technology development, through institutional inertial [10] where host country regulations, standards, and expectations affect foreign firm adaptation and performance [96].

Based on the review, we infer that not all proximity dimensions are equal, which must be reflected in interpretation of the findings. Knowledge transfer does not occur spontaneously as actors must have minimum level of similarity, as well as heterogeneity to communicate, understand, and learn effectively. Cognitive, social, and institutional proximities are important components that interrelates with other proximities. Cognitive proximity is important as it significantly interplays with other proximities. Without shared understanding, no matter how geographically proximate actors are, learning and communication will be difficult, and therefore innovation can be constrained. Lack of cognitive proximity is comparable to listening to unfamiliar language that unless translated for understanding, will not amount to communication progress. Therefore, valuable knowledge as well as ability to communicate and understand through shared expertise increases potential for knowledge transfer and sustained technology development. Social proximity is important because, assuming 
there is cognitive proximity, without trust or social ties, individuals will be hesitant to engage in knowledge transfer. In other words, trust can encourage actors to engage in communication that increases likelihood for knowledge transfer. Put differently, it is likely for actors with shared expertise (cognitive proximity) and trust for one another to engage in knowledge transfer activities, compared to less familiar actors with shared expertise. Institutional proximity is important because it coordinates and manages cognitive and social element. We use an example to make the point. Consider actors that engage in knowledge transfer activities from shared expertise and trust but transact knowledge assets inappropriately. Depending on the circumstance, such act can range from violations, infringement to abuse even though knowledge transfer meets condition of shared expertise (cognitive proximity) and trust (social proximity). The point is institutional proximity ensures regulations and laws guide actor's behavior during knowledge transfer activities.

Overall, there is interplay among the five proximities. For example, social proximity transcends boundaries as individuals can interact from distance; assuming conditions (such as trust and shared understanding) are favorable for collaboration. On the other hand, geographical proximity enables social proximity as collocation increases likelihood for interaction, communication, and potential collaboration. Similarly, geographically proximity such as science parks increases likelihood for cognitive proximity in terms of interaction and collaboration among individuals with shared expertise. It is relatively easier to facilitate knowledge transfer for innovation and sustained technology development between individuals from similar corporate group (organizational proximity), as organized systems and incentives improves communication and reduce uncertainty for intra-organizational collaboration for geographically proximate and distance entities. Furthermore, institutional frameworks such as regulations, laws and norms govern knowledge transfer activities (other proximities) both for proximate and distance actors. On the other hand, firms and actors can stimulate institutional frameworks (regulations, laws, norms) to govern behavior and activities of proximate and distant firms.

Therefore, each proximity encourages and reinforces proximity in other dimension but there are important basic requirements of knowledge similarity, trust and regulation that must exist for proximity to be used responsibly. Otherwise, there is a chance that connection among proximities can hinder technology development. For example, weak institutional (or lack of) regulation for knowledge assets can undermine and abuse knowledge flow, and consequently signal distrust that reduces collaboration opportunities. Similarly, there is a chance that cognitively proximate actors might miss out on innovation that occurs through interdisciplinary interactions because of need to maintain collaboration with partners that share similar expertise. Some innovation ideas come from customers, supply chains and competitors. However, if cognitive proximity leads to complacency, then potential opportunities in other areas may not be explored. Centrally managed knowledge assets can protect corporate knowledge, but there is a chance that technology development can be hindered because actors may not freely interact with potential partners except determined by corporate group (organizational proximity). Since ideas can come from outside corporate entities, then organizational proximity may limit flexibility and reduce knowledge flow. Although interaction with actors outside corporate entity, and cross-industry collaboration may present challenges such as conflict of interest, misaligned objective that can hinder sustained technology development, but can potentially increase likelihood for interdisciplinary collaboration. Therefore, optimal proximity that manages downsides and strengthens potential for synergy through knowledge transfer can lead to sustained technology development.

\section{Implications for Practice and Research}

The aim of the review was to provide understanding on ways that spatial and non-spatial proximities are measured and influence sustained technology development. The result of the current study has important implication for practice, in terms of design of R\&D policies geared at facilitating knowledge transfer through network for sustained technology development. The finding 
that proximities are associated with sustained technology development suggest knowledge sources should be tailored to favorable characteristics of proximities to enhance technology development for competitiveness. Contents of R\&D policies may need to be varied to use in-house competencies as well as external knowledge sources through the different proximities to provide synergies for innovation.

The review suggests that proximities influence sustained technology development by developing innovation and knowledge networks. However, for measurements, we recommend that future research should be mindful of peculiarities and adopt flexible measurement indicators more compatible with contextual factors to further our understanding on ways that proximities affects performance in such context.

The current review has some limitations. Although the selection process aimed to cover comprehensive scientific databases, we recognize that some articles might have been unnoticed as it was limited by search terms used, academic literature included, and time period of published literature that was included in the study. The review excluded speculative and grey literature because it was important to ground our understanding in research evidence rather than speculation. The limitations should be considered in interpretation of discussion of findings presented above.

\section{Conclusions}

The review in the current study contains valuable information for policy makers, manager, and researchers involved in planning activities aimed at understanding, managing, and improving knowledge flow. The findings from the review suggest that strategies based on regional peculiarities are important for policies that encourage knowledge transfer, through proximity, towards improving capacity for sustainable technology development that can be used to address environmental and social-economic challenges. Developing knowledge base for sustainable technology development must have a resonance with policy needs to facilitate planning on ways that knowledge flows can meet policy and sustainability agenda. Proximities influence technology development for competitiveness through knowledge transfer, trust building and collaboration that leads to synergy for innovation. Each dimension was measured mostly with patent related information, and in developed countries, which makes the findings less extensible to developing countries. Therefore, future work would benefit from a more careful, theory led application of the concept of proximity. We recommend that such studies take into consideration criteria of availability (of data to relevant public) and cost efficiency from perspective of developing countries.

Furthermore, development in technology has facilitated other virtual medium of communication alternatives. The review shows that intangible components are important for knowledge transfer to take place, as value of knowledge does not depend entirely on location. There are important interpersonal factors that influence knowledge spillover. The review showed that knowledge spillover requires some level of similarity in terms of knowledge background between actors for understanding and learning to occur easily, exemplified by the concept of cognitive proximity. Organizational proximity suggests there are certain connections and attributes that some organizations have in common which determines their capacity to work together and acquire external knowledge from other sources. For example, incentives of academia can be different from that of profit-driven organizations, which can influence their collaboration objectives and performance. The main ideas of social proximity are that interpersonal relations can develop trust that in turn leads to learning, knowledge transfer, and collaboration. In addition, institutional proximity suggests there are underlying institutional frameworks such as regulations, laws, norms, language, religious values, and culture shared by actors that must not be taken for granted because they can facilitate or hinder knowledge spillover. All these factors suggest that we cannot ignore the non-spatial factors, as they influence knowledge transfer, and eventually how transferred knowledge is managed and translated into sustained technological development. 
Author Contributions: Conceptualization, O.C. and S.-H.C., methodology, O.C. and S.-H.C., formal analysis, O.C., data curation, O.C., writing-original draft preparation, O.C., Writing-review and editing, O.C., and S.-H.C.; supervision, S.-H.C.

Funding: This research was partially funded by Ministry of Science and Technology (R.O.C, Taiwan), grant number MOST 106-2410-H-009-001-MY2.

Acknowledgments: The authors would like to thank four anonymous reviewers for constructive comments on earlier version of the manuscript, which significantly improved this paper. The views expressed and remaining errors are our own.

Conflicts of Interest: The authors declare no conflict of interest.

\section{Appendix A}

Table A1. Summary of proximities from literature review.

\section{Categories and Brief \\ Definitions}

Summary of Key Ideas

\section{Geographical proximity} refers to similarity of important spatial component that focuses on absolute physical closeness or relative distance between actors within a territorial unit or location.
Time distance (traffic intensity) is important than spatial distance [17,21,27], as shorter travel distance between partners affect innovative outcomes [27]. Tacit knowledge can be geographically bounded than codified knowledge [28]. Therefore, geographical proximity strengthens learning and transfer of tacit knowledge $[12,15,18]$, that are highly concentrated in territorial locations [19].

- Geographical proximity enhances face-to-face interaction, informal relations and human resources connections between actors that can be sources of knowledge flow for improved R\&D activities [29,31,32].

- With face-to-face advantages, geographical proximity can facilitate mutual trust between partners for collaboration on innovation activities [20]. In addition, knowledge externalities attract economic development and further knowledge-production activities [28].

- Geographical proximity provides information advantage for local actors over distant actors [33].

- Optimal distance requires balance between geographical proximity and distance that will not hinder innovation through lock-in [15,34].

- Geographical distance provides access to heterogeneous resources for new knowledge recombination [26] and avoids lock-in and complacency [34].
Cognitive proximity refers to the degree of similarity in partner's background knowledge in terms of their education, discipline, expertise, and proficiencies, which facilitates interaction, knowledge transfer, and use of knowledge assets.
Openness to external knowledge sources depends on firm's cognitive ability in specific knowledge field $[10,12,45]$, familiarity and ability to reuse external knowledge $[10,46-48]$ that provides valuable resources for competitiveness $[51,53]$.

- $\quad$ Cognitive proximity allows for easy learning, mutual understanding through absorptive capacity $[49,50,60]$, reduces communication friction [20] and improves path of knowledge buildup for [64] innovation activities [27,41].

- $\quad$ Cognitively proximate firms are targets are potential targets for mergers and acquisition because of technological relatedness [62].

- $\quad$ Interaction with global sources can create knowledge for innovation [3,44]. However, only firms with valuable resources can attract qualified partners in networks [50].

- $\quad$ Cognitive distance attracts complementary new knowledge from afar for creativity, radical innovation and to avoid cognitive lock-in $[10,46,53,59,60,63]$.

- $\quad$ Cognitive proximity can lead to risk of involuntary knowledge spillover if not properly managed [10]. Therefore, network capabilities are required to manage inter-organizational relationship $[54,57,58]$, at different levels of complexities [50] that provides competitive advantage through interaction between internal and external capabilities [55]. 
Table A1. Cont.

Categories and Brief Definitions

Organizational proximity refers to the extent that partners identify with the routines of an organization, and their membership to similar organizational entity, which influences interaction, and knowledge transfer.
Summary of Key Ideas

Organizational proximity is relevant for exploitative relationship that applies to search intensity within existing knowledge domains [74].

- Organizational proximity provides communication and coordination framework [79] aligned towards complementary objectives, structure, organizational culture [80] and knowledge potential of actors [77,78].

- Organizational proximity reflects homogenous routines, incentives, and contractual affiliation $[38,75,76]$ that facilitates smooth collaboration among actors $[73,74]$.

Organizational proximity improves positive bilateral collaboration when there is common organizational characteristics [81], improves marginal productivity for proximal partner [37], reduces barrier and opportunism threats to knowledge transfer [26].

- $\quad$ Organizational proximity control knowledge diffusion and decreases transaction cost $[10,12]$.
Social proximity refers to ties of personal relationship such as family connection, previous collaborations, friendship, and affection that exist between actors, which enables them to trust each other, use and transfer knowledge assets.
Trust is an important component for knowledge transfer within social circles [57]. Therefore, trust among social ties reduces opportunism, facilitates knowledge transfer [10,49,83-85].

- $\quad$ Social proximity facilitates knowledge transfer and transfer of tacit knowledge [86,87].

- $\quad$ Social proximity allows actors within ethnic communities to exchange knowledge across long distance (from host country to home country for technology development) $[88,90,91]$.

- $\quad$ Social proximity facilitates knowledge spillover within social networks through mutual trust and interaction, a privilege that can only be available to network actors [89].

- Social proximity can create complacency that hinders innovation, as actors over rely on social ties for knowledge and information [10].

\section{Institutional proximity}

refers to the extent of similarities in institutional framework between countries or regions of actors, in terms of regulations, standards and expectations that affects interaction, and use of knowledge assets.
Institutional proximity (laws, rules, norms and values) can provide favorable conditions for knowledge exchange, interaction $[10,13]$ and stability for cooperative behavior among actors [95].

- Regulatory, normative and cognitive proximities are aimed at legitimacy and compliance with regulations and standards that can affect innovation performance $[94,96,97]$.

- Institutional proximity can reduce uncertainty and transaction cost for interaction, and knowledge transfer $[10,13,20,84]$.

- Institutional distance can lead to institutional inertia that hinders interactive learning and institutional reforms [10,102]. In the sense that large institutional distance reduces knowledge spillover [100], inhibits collaboration in host countries, and increases dependence on less formal institutions to avoid opportunism and risks [20].

- Institutional distance increase liability of foreignness and unfamiliarity hazards faced by foreign firms that do not apply to local firms [103-106] that limits resources to foreign firms [111], and potentially discourages entry $[107,108]$.

- Institutional distance can lead to opportunistic behavior because foreign firms are unfamiliar with host country [112,115], lack of trust [113], and insufficient information in host country [110,116,117].

Institutional distance can constrain firms activities [95], that affects ability to transfer resources and practices to different context [118]. 
Table A2. Summary of measurements for proximities from literature review.

\begin{tabular}{|c|c|}
\hline Proximities & Measurement Variables \\
\hline $\begin{array}{l}\text { Geographical } \\
\text { proximity }\end{array}$ & 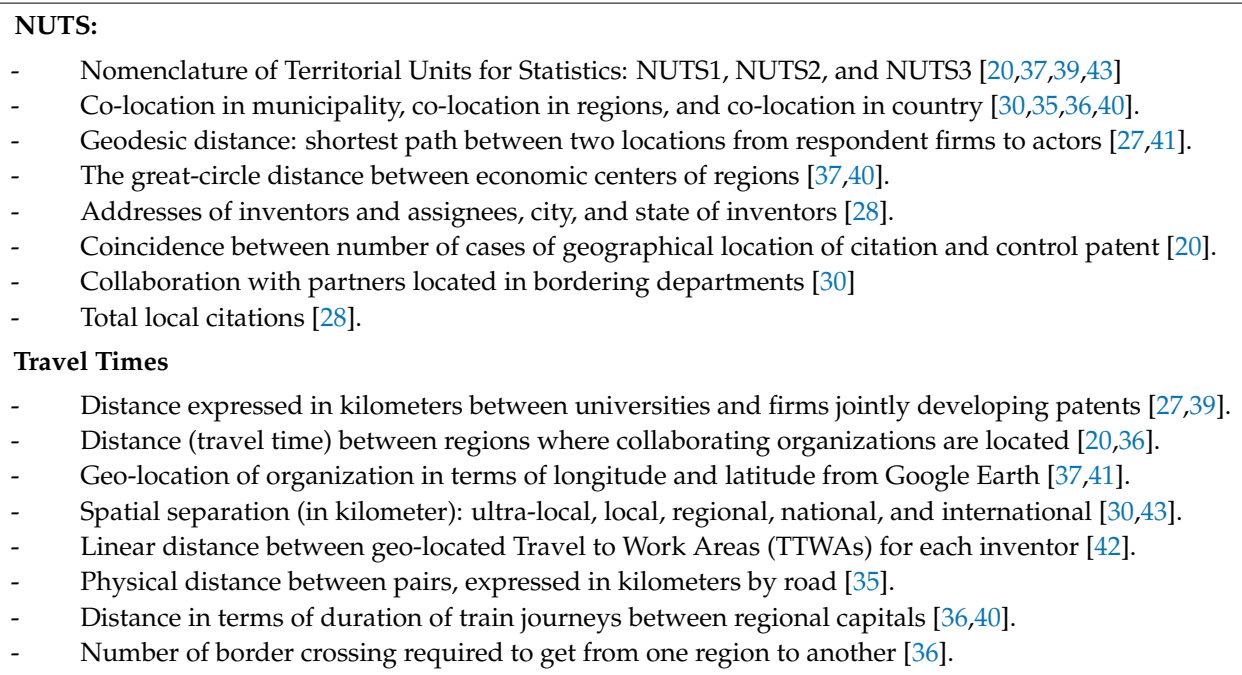 \\
\hline $\begin{array}{l}\text { Cognitive } \\
\text { Proximity }\end{array}$ & 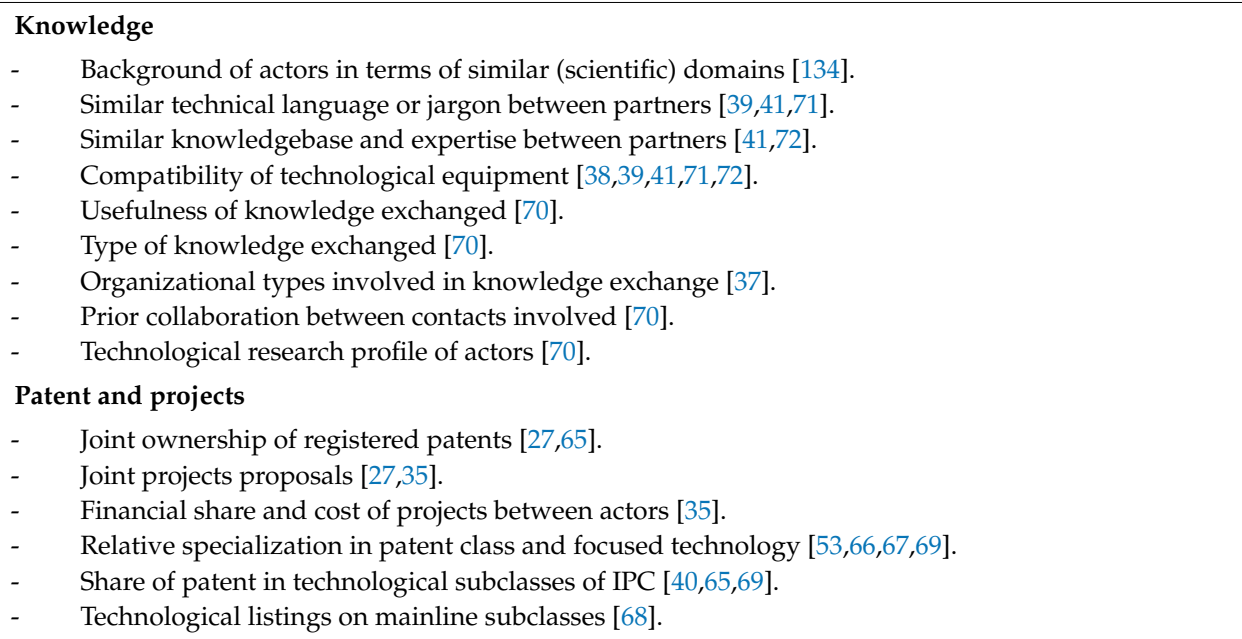 \\
\hline $\begin{array}{l}\text { Organizational } \\
\text { proximity }\end{array}$ & $\begin{array}{l}\text { Physical Distance } \\
\text { - } \quad \text { Physical distance (kilometers) between firm's headquarters and province capital where firm is } \\
\text { located [33,82]. } \\
\text { Ownership } \\
\text { - } \quad \text { Whether actors (two firms) belong to same corporate group [38,82]. } \\
\text { - } \quad \text { Whether inventor shares in patent application [42]. } \\
\text { Industry } \\
\text { - } \quad \text { Organizations type in terms of academic or non-academic character [37]. } \\
\text { Rigidness } \\
\text { - } \quad \text { Degree of difference between firm and partner in adapting to new circumstances [41]. } \\
\text { - } \quad \text { Degree of compliance in adhering to strict planning and financial management between actors [41]. } \\
\text { - } \quad \text { Degree of freedom to initiate relations outside respective organizations of actors [41]. } \\
\text { - } \quad \text { Degree of compliance in preference to procedures to achieving results between actors [39,41]. } \\
\text { - } \quad \text { Whether actors have established organizational routines to work together [43]. }\end{array}$ \\
\hline
\end{tabular}


Table A2. Cont.

\begin{tabular}{|c|c|}
\hline Proximities & Measurement Variables \\
\hline \multirow{11}{*}{$\begin{array}{l}\text { Social } \\
\text { Proximity }\end{array}$} & Network connections \\
\hline & $\begin{array}{l}\text { - Degree of linkages by cited patents and citations in terms of direct, indirect linkages between } \\
\text { patents (geodesic distance 2) }[35,38,42,92,93] \text {. }\end{array}$ \\
\hline & - $\quad$ Network position of partners in prior period [35]. \\
\hline & - $\quad$ Whether pairs jointly submitted a proposal to the Framework program [35,42]. \\
\hline & - Whether pairs have co-invented previously and joint financing arrangement [42,92]. \\
\hline & Interpersonal relations \\
\hline & - $\quad$ Familiarity between individuals in terms of private lives [71]. \\
\hline & - $\quad$ Emotional support between individuals in terms of concerns for actor's wellbeing [71]. \\
\hline & - $\quad$ Degree of personal obligation to provide support regardless of time required [41,71]. \\
\hline & Level of trust in contribution to partners [41]. \\
\hline & Openness to share information [41]. \\
\hline \multirow{9}{*}{$\begin{array}{l}\text { Institutional } \\
\text { Proximity }\end{array}$} & Country-level orientation \\
\hline & $\begin{array}{l}\text { - Cultural distance: power distance, uncertainty avoidance, individualism/collectivism, } \\
\text { and masculinity/femininity [40,122]. }\end{array}$ \\
\hline & Economic distance: financial market differences between countries [122]. \\
\hline & - $\quad$ Regulatory distance: industry activity regulations and competition regulations [122]. \\
\hline & Political distance: political systems, political volatility within a country [40,122]. \\
\hline & - $\quad$ Similar (or different) language areas $[40,122]$ \\
\hline & Institutional forms \\
\hline & - $\quad$ The actor sector $[20,134]$ \\
\hline & - $\quad$ Degree of similarity in actor organization (such as academia-academia) $[20,38,122,123]$. \\
\hline
\end{tabular}

\section{References}

1. Asheim, B.T. Regional Innovation Policy for Small-Medium Enterprises; Asheim, B.T., Ed.; Edward Elgar: Cheltenham, UK, 2003.

2. Bos-Brouwers, H.E. Corporate sustainability and innovation in SMEs: Evidence of themes and activities in practice. Bus. Strategy Environ. 2009, 19, 417-435. [CrossRef]

3. Asheim, B.; Gertler, M. The geography of innovation: Regional innovation systems. In The Oxford Handbook of Innovation; Fagerberg, J.J., Mowery, D.C., Nelson, R.R., Eds.; Oxford University Press: Oxford, UK, 2005.

4. López-Bazo, E.; Vayá, E.; Artís, M. Regional Externalities and Growth: Evidence from European Regions. J. Reg. Sci. 2004, 44, 43-73. [CrossRef]

5. Audretsch, D.B.; Feldman, M.P. R\&D spillovers and the geography of innovation and production. Am. Econ. Rev. 1996, 86, 630-640.

6. Dicken, P.; Malmberg, A. Firms in Territories: A Relational Perspective. Econ. Geogr. 2001, 77, $345-363$. [CrossRef]

7. Torre, A.; Rallet, A. Proximity and Localization. Reg. Stud. 2005, 39, 47-59. [CrossRef]

8. Moulaert, F.; Sekia, F. Territorial Innovation Models: A Critical Survey. Reg. Stud. 2003, 37, $289-302$. [CrossRef]

9. Lundquist, K.-J.; Trippl, M. Distance, Proximity and Types of Cross-border Innovation Systems: A Conceptual Analysis. Reg. Stud. 2013, 47, 450-460. [CrossRef]

10. Boschma, R. Proximity and Innovation: A Critical Assessment. Reg. Stud. 2005, 39, 61-74. [CrossRef]

11. Cooper, H. Research Synthesis and Meta-Analysis: A Step-by-Step Approach, 4th ed.; Sage: Thousand Oaks, CA, USA, 2010.

12. Knoben, J.; Oerlemans, L.A.G. Proximity and inter-organizational collaboration: A literature review. Int. J. Manag. Rev. 2006, 8, 71-89. [CrossRef]

13. Mattes, J. Dimensions of Proximity and Knowledge Bases: Innovation between Spatial and Non-spatial Factors. Reg. Stud. 2012, 46, 1085-1099. [CrossRef]

14. Bouba-Olga, O.; Grossetti, M. Socio-économie de proximité. Rev. D'économie Régionale Urbaine 2008, 3, 311-328. [CrossRef] 
15. Broekel, T.; Boschma, R. Knowledge networks in the Dutch aviation industry: The proximity paradox. J. Econ. Geogr. 2012, 12, 409-433. [CrossRef]

16. Seuring, S.; Müller, M. From a literature review to a conceptual framework for sustainable supply chain management. J. Clean. Prod. 2008, 16, 1699-1710. [CrossRef]

17. MacEachren, A.M. Travel time as the basis of cognitive distance. Prof. Geogr. 1980, 32, 30-36. [CrossRef]

18. Torre, A.; Gilly, J.-P. On the Analytical Dimension of Proximity Dynamics. Reg. Stud. 2000, 34, 169-180.

19. Simmie, J. Innovation and Urban Regions as National and International Nodes for the Transfer and Sharing of Knowledge. Reg. Stud. 2003, 37, 607-620. [CrossRef]

20. Ponds, R.; van Oort, F.; Frenken, K. The geographical and institutional proximity of research collaboration. Pap. Reg. Sci. 2007, 86, 423-443. [CrossRef]

21. Golledge, R.G.; Zannaras, G. Cognitive Approaches to the Analysis of Human Spatial Behavior; Environment and Cognition; Ittelson, W., Ed.; Seminar Press: New York, NY, USA, 1973; pp. 59-94.

22. Ruhleder, K.; Green, C. Globalization, borderless worlds, and the Tower of Babel: Metaphors gone awry. J. Organ. Chang. Manag. 1995, 8, 55-68.

23. Farazmand, A. Globalization and Public Administration. Public Adm. Rev. 1999, 59, 509-522. [CrossRef]

24. Griffith, T.L.; Sawyer, J.E.; Neale, M.A. Virtualness and Knowledge in Teams: Managing the Love Triangle of Organizations, Individuals, and Information Technology. Mis Q. 2003, 27, 265-287. [CrossRef]

25. Doloreux, D.; Parto, S. Regional innovation systems: Current discourse and unresolved issues. Technol. Soc. 2005, 27, 133-153. [CrossRef]

26. Capaldo, A.; Petruzzelli, A.M. Partner Geographic and Organizational Proximity and the Innovative Performance of Knowledge-Creating Alliances. Eur. Manag. Rev. 2014, 11, 63-84. [CrossRef]

27. Petruzzelli, A.M. The impact of technological relatedness, prior ties, and geographical distance on university-industry collaborations: A joint-patent analysis. Technovation 2011, 31, 309-319. [CrossRef]

28. Sonn, J.W.; Storper, M. The Increasing Importance of Geographical Proximity in Knowledge Production: An Analysis of US Patent Citations, 1975-1997. Environ. Plan. A Econ. Space 2008, 40, 1020-1039. [CrossRef]

29. Vedovello, C. Science parks and university-industry interaction: Geographical proximity between the agents as a driving force. Technovation 1997, 17, 491-531. [CrossRef]

30. Gallié, E.-P. Is Geographical Proximity Necessary for Knowledge Spillovers within a Cooperative Technological Network? The Case of the French Biotechnology Sector. Reg. Stud. 2009, 43, 33-42. [CrossRef]

31. Rallet, A.; Torre, A. Is geographical proximity necessary in the innovation networks in the era of global economy? GeoJournal 1999, 49, 373-380. [CrossRef]

32. Capello, R.; Faggian, A. Collective Learning and Relational Capital in Local Innovation Processes. Reg. Stud. 2005, 39, 75-87. [CrossRef]

33. Jiménez, G.; Salas, V.; Saurina, J. Organizational distance and use of collateral for business loans. J. Bank. Financ. 2009, 33, 234-243. [CrossRef]

34. Boschma, R.; Frenken, K. The Spatial Evolution of Innovation Networks: A Proximity Perspective. In The Handbook of Evolutionary Economic Geography; Martin, R.B.a.R., Ed.; Edward Elgar: Cheltenham, UK; Northampton, MA, USA, 2010; pp. 120-135.

35. Autant-Bernard, C.; Billand, P.; Frachisse, D.; Massard, N.; Autant-Bernard, C. Social distance versus spatial distance in R\&D cooperation: Empirical evidence from European collaboration choices in micro and nanotechnologies. Pap. Reg. Sci. 2007, 86, 495-519.

36. Bouba-Olga, O.; Ferru, M.; Pépin, D. Exploring spatial features of science-industry partnerships: A study on French data. Pap. Reg. Sci. 2011, 91, 355-375. [CrossRef]

37. Cunningham, S.W.; Werker, C. Proximity and collaboration in European nanotechnology. Pap. Reg. Sci. 2012, 91, 723-742. [CrossRef]

38. Balland, P.-A. Proximity and the Evolution of Collaboration Networks: Evidence from Research and Development Projects within the Global Navigation Satellite System (GNSS) Industry. Reg. Stud. 2012, 46, 741-756. [CrossRef]

39. Aguiléra, A.; Lethiais, V.; Rallet, A. Spatial and Non-spatial Proximities in Inter-firm Relations: An Empirical Analysis. Ind. Innov. 2012, 19, 187-202. [CrossRef]

40. Barber, M.J.; Scherngell, T. Is the European R\&D Network Homogeneous? Distinguishing Relevant Network Communities Using Graph Theoretic and Spatial Interaction Modelling Approaches. Reg. Stud. 2013, $47,1283-1298$. 
41. Heringa, P.W.; Horlings, E.; Van Der Zouwen, M.; Besselaar, P.V.D.; Van Vierssen, W. How do dimensions of proximity relate to the outcomes of collaboration? A survey of knowledge-intensive networks in the Dutch water sector. Econ. Innov. New Technol. 2014, 23, 689-716. [CrossRef]

42. Crescenzi, R.; Nathan, M.; Rodríguez-Pose, A. Do inventors talk to strangers? On proximity and collaborative knowledge creation. Res. Policy 2016, 45, 177-194. [CrossRef]

43. Lazzeretti, L.; Capone, F. How proximity matters in innovation networks dynamics along the cluster evolution. A study of the high technology applied to cultural goods. J. Bus. Res. 2016, 69, 5855-5865. [CrossRef]

44. Boschma, R.; Iammarino, S. Related Variety, Trade Linkages, and Regional Growth in Italy. Econ. Geogr. 2009, 85, 289-311. [CrossRef]

45. Capello, R. Spatial Spillovers and Regional Growth: A Cognitive Approach. Eur. Plan. Stud. 2009, 17, 639-658. [CrossRef]

46. Wuyts, S.; Colombo, M.G.; Dutta, S.; Nooteboom, B. Empirical tests of optimal cognitive distance. J. Econ. Behav. Organ. 2005, 58, 277-302. [CrossRef]

47. Cantner, U.; Meder, A. Technological proximity and the choice of cooperation partner. J. Econ. Interact. Coord. 2007, 2, 45-65. [CrossRef]

48. Nooteboom, B. Learning by interaction: Absorptive capacity, cognitive distance and governance. J. Manag. Gov. 2000, 4, 69-92. [CrossRef]

49. Werker, C.; Ooms, W.; Caniels, M.C. Personal and related kinds of proximity driving collaborations: A multi-case study of Dutch nanotechnology researchers. Springerplus 2016, 5, 1751. [CrossRef] [PubMed]

50. Möller, K.K.; Halinen, A. Business Relationships and Networks: Managerial Challenge of Network Era. Ind. Mark. Manag. 1999, 28, 413-427. [CrossRef]

51. Castro, G.M.-D.; Delgado-Verde, M.; Navas-López, J.E.; Cruz-González, J. The moderating role of innovation culture in the relationship between knowledge assets and product innovation. Technol. Forecast. Soc. Chang. 2013, 80, 351-363. [CrossRef]

52. Noruzy, A.; Dalfard, V.M.; Azhdari, B.; Nazari-Shirkouhi, S.; Rezazadeh, A. Relations between transformational leadership, organizational learning, knowledge management, organizational innovation, and organizational performance: An empirical investigation of manufacturing firms. Int. J. Adv. Manuf. Technol. 2013, 64, 1073-1085. [CrossRef]

53. Gilsing, V.; Nooteboom, B.; Vanhaverbeke, W.; Duysters, G.; Oord, A.V.D. Network embeddedness and the exploration of novel technologies: Technological distance, betweenness centrality and density. Res. Policy 2008, 37, 1717-1731. [CrossRef]

54. Ritter, T. The Networking Company: Antecedents for Coping with Relationships and Networks Effectively. Ind. Mark. Manag. 1999, 28, 467-479. [CrossRef]

55. Foss, N.J. Networks, capabilities, and competitive advantage. Scand. J. Manag. 1999, 15, 1-15. [CrossRef]

56. Burt, R.S. Structural Holes: The Social Structure of Competition; Harvard University Press: Cambridge, MA, USA, 1995.

57. Ritter, T.; Gemünden, H.G. Network competence: Its impact on innovation success and its antecedents. J. Bus. Res. 2003, 56, 745-755. [CrossRef]

58. Walter, A.; Auer, M.; Ritter, T. The impact of network capabilities and entrepreneurial orientation on university spin-off performance. J. Bus. Ventur. 2006, 21, 541-567. [CrossRef]

59. Visser, E.-J.; Boschma, R. Learning in districts: Novelty and lock-in in a regional context. Eur. Plan. Stud. 2004, 12, 793-808. [CrossRef]

60. Nooteboom, B.; Van Haverbeke, W.; Duysters, G.; Gilsing, V.; Oord, A.V.D. Optimal cognitive distance and absorptive capacity. Res. Policy 2007, 36, 1016-1034. [CrossRef]

61. Nooteboom, B. Learning and Innovation in Organizations and Economies; Oxford University Press: Oxford, UK, 2000.

62. Hussinger, K. On the importance of technological relatedness: SMEs versus large acquisition targets. Technovation 2010, 30, 57-64. [CrossRef]

63. Enkel, E.; Heil, S. Preparing for distant collaboration: Antecedents to potential absorptive capacity in cross-industry innovation. Technovation 2014, 34, 242-260. [CrossRef]

64. Shin, J.; Jalajas, D. Technological relatedness, boundary-spanning combination of knowledge and the impact of innovation: Evidence of an inverted-U relationship. J. High Technol. Manag. Res. 2010, 21, 87-96. [CrossRef] 
65. Jaffe, A.B. Characterizing the "technological position" of firms, with application to quantifying technological opportunity and research spillovers. Res. Policy 1989, 18, 87-97. [CrossRef]

66. Benner, M.; Waldfogel, J. Close to you? Bias and precision in patent-based measures of technological proximity. Res. Policy 2008, 37, 1556-1567. [CrossRef]

67. vom Stein, N.; Sick, N.; Leker, J. How to measure technological distance in collaborations-The case of electric mobility. Technol. Forecast. Soc. Chang. 2015, 97, 154-167. [CrossRef]

68. Aharonson, B.S.; Schilling, M.A. Mapping the technological landscape: Measuring technology distance, technological footprints, and technology evolution. Res. Policy 2016, 45, 81-96. [CrossRef]

69. Schoen, A.; Villard, L.; Laurens, P.; Cointet, J.P.; Heimeriks, G.; Alkemade, F. The Network Structure of Technological Developments; Technological Distance as a Walk on the Technology Map. In Proceedings of the International Conference on Science and Technology Indicators, Montréal, QC, Canada, 5-8 September 2012.

70. Weterings, A.; Ponds, R. Do Regional and Non-regional Knowledge Flows Differ? An Empirical Study on Clustered Firms in the Dutch Life Sciences and Computing Services Industry. Ind. Innov. 2009, 16, 11-31. [CrossRef]

71. Huber, F. On the Role and Interrelationship of Spatial, Social and Cognitive Proximity: Personal Knowledge Relationships of R\&D Workers in the Cambridge Information Technology Cluster. Reg. Stud. 2012, $46,1169-1182$.

72. Inkmann, J.; Pohlmeier, W. R\&D Spillovers, Technological Distance and Innovative Success. In $R \mathcal{E} D$, Innovation and Productivity; Institute for Fiscal Studies: London, UK, 1995.

73. Broekel, T.; Binder, M. The Regional Dimension of Knowledge Transfers-A Behavioral Approach. Ind. Innov. 2007, 14, 151-175. [CrossRef]

74. Petruzzelli, A.M. Proximity and knowledge gatekeepers: The case of the Polytechnic University of Turin. J. Knowl. Manag. 2008, 12, 34-51. [CrossRef]

75. D’Este, P.; Iammarino, S. The spatial profile of university-business research partnerships. Pap. Reg. Sci. 2010, 89, 335-350. [CrossRef]

76. D'Este, P.; Guy, F.; Iammarino, S. Shaping the formation of university-Industry research collaborations: What type of proximity does really matter? J. Econ. Geogr. 2013, 13, 537-558. [CrossRef]

77. Ernst, D. The new mobility of knowledge: Digital information systems and global flagship networks. Digital formations. In IT and New Architectures in the Global Realm; Latham, R., Sassen, S., Eds.; Princeton University Press: Princeton, NJ, USA, 2005.

78. Gereffi, G.; Humphrey, J.; Sturgeon, T. The governance of global value chains. Rev. Int. Political Econ. 2005, 12, 78-104. [CrossRef]

79. Dosi, G.; Marengo, L. Some elements of evolutionary theory of organizational competences. In Evolutionary Concepts in Contemporary Economics; England, R., Ed.; University of Michigan Press: Ann Arbor, MI, USA, 1994.

80. Perkmann, M.; Tartari, V.; McKelvey, M.; Autio, E.; Broström, A.; D’este, P.; Fini, R.; Geuna, A.; Grimaldi, R.; Hughes, A.; et al. Academic engagement and commercialisation: A review of the literature on university-industry relations. Res. Policy 2013, 42, 423-442. [CrossRef]

81. Picci, L. The internationalization of inventive activity: A gravity model using patent data. Res. Policy 2010, 39, 1070-1081. [CrossRef]

82. Fiordelisi, F.; Monferrà, S.; Sampagnaro, G. Relationship Lending and Credit Quality. J. Financ. Serv. Res. 2014, 46, 295-315. [CrossRef]

83. Caniëls, M.C.J.; Kronenberg, K.; Werker, C. Conceptualizing Proximity in Research Collaborations Between Universities and Firms. In The Social Dynamics of Innovation Networks; Rutten, R., Benneworth, P., Irawati, D., Boekema, F., Eds.; Routledge: Abingdon, UK, 2014.

84. Maskell, P.; Malmberg, A. The Competitiveness of Firms and Regions: 'Ubiquitification' and the Importance of Localized Learning. Eur. Urban Reg. Stud. 1999, 6, 9-25. [CrossRef]

85. Amin, A.; Cohendet, P. Geographies of Knowledge Formation in Firms. Ind. Innov. 2005, 12, $465-486$. [CrossRef]

86. Nooteboom, B.; Gilsing, V.A. Density and Strength of Ties in Innovation Networks: A Competence and Governance View; Tilburg University: Tilburg, The Netherlands, 2005.

87. Granovetter, M. Economic Action and Social Structure: The Problem of Embeddedness. Am. J. Sociol. 1985, 91, 481-510. [CrossRef] 
88. Saxenian, A.L. Silicon Valley's New Immigrant Entrepreneurs; Public Policy Institute of California: San Francisco, CA, USA, 1999.

89. Breschi, S.; Lissoni, F. Mobility of skilled workers and co-invention networks: An anatomy of localized knowledge flows. J. Econ. Geogr. 2009, 9, 439-468. [CrossRef]

90. Agrawal, A.; Kapur, D.; McHale, J. How do spatial and social proximity influence knowledge flows? Evidence from patent data. J. Urban Econ. 2008, 64, 258-269. [CrossRef]

91. Agrawal, A.; Cockburn, I.; McHale, J. Gone but not forgotten: Knowledge flows, labor mobility, and enduring social relationships. J. Econ. Geogr. 2006, 6, 571-591. [CrossRef]

92. Breschi, S.; Lissoni, F. Mobility and Social Networks: Localised Knowledge Spillovers Revisited; University Bocconi: Milan, Italy, 2003.

93. Snijders, T.A.B.; van de Bunt, G.G.; Steglich, C.E.G. Introduction to stochastic actor-based models for network dynamics. Soc. Netw. 2010, 32, 44-60. [CrossRef]

94. North, D.C. Institutions. J. Econ. Perspect. 1991, 5, 97-112. [CrossRef]

95. Xu, D.; Shenkar, O. Institutional Distance and the Multinational Enterprise. Acad. Manag. Rev. 2002, 27, 608-618. [CrossRef]

96. Scott, W.R. Institutions and Organizations; SAGE: Thousand Oaks, CA, USA, 1995.

97. North, D.C. Institutions, Institutional Change and Economic Performance; Cambridge University Press: Cambridge, UK, 1990.

98. Kostova, T. Transnational Transfer of Strategic Organizational Practices: A Contextual Perspective. Acad. Manag. Rev. 1999, 24, 308-324. [CrossRef]

99. Kostova, T.; Zaheer, S. Organizational Legitimacy under Conditions of Complexity: The Case of the Multinational Enterprise. Acad. Manag. Rev. 1999, 24, 64-81. [CrossRef]

100. Higón, D.A.; Manjón-Antolín, M. International R\&D Spillovers, TFP and Institutional Distance. In International Business and Institutions after the Financial Crisis; Temouri, Y., Jones, C., Eds.; Palgrave Macmillan: London, UK, 2014; pp. 267-280.

101. Hong, W.; Su, Y.-S. The effect of institutional proximity in non-local university-industry collaborations: An analysis based on Chinese patent data. Res. Policy 2013, 42, 454-464. [CrossRef]

102. Dasgupta, P.; David, P.A. Toward a new economics of science. Res. Policy 1994, 23, 487-521.

103. Eden, L.; Miller, S.R. Distance matters: Liability of foreignness, institutional distance and ownership strategy. In Theories of the Multinational Enterprise: Diversity, Complexity and Relevance; Emerald Group Publishing Limited: Bingley, UK, 2004; pp. 187-221.

104. Zaheer, S. Overcoming the Liability of Foreignness. Acad. Manag. J. 1995, 38, 341-363.

105. Kostova, T. Country institutional profiles: Concept and measurement. Acad. Manag. Proc. 1997, 1, $180-184$. [CrossRef]

106. Zaheer, S.; Mosakowski, E. The Dynamics of the Liability of Foreignness: A Global Study of Survival in Financial Services. Strateg. Manag. J. 1997, 18, 439-463. [CrossRef]

107. Berry, H.; Guillén, M.F.; Zhou, N. An institutional approach to cross-national distance. J. Int. Bus. Stud. 2010, 41, 1460-1480. [CrossRef]

108. Sun, P.; Mellahi, K.; Thun, E. The dynamic value of MNE political embeddedness: The case of the Chinese automobile industry. J. Int. Bus. Stud. 2010, 41, 1161-1182. [CrossRef]

109. Schmidt, T.; Sofka, W. Liability of foreignness as a barrier to knowledge spillovers: Lost in translation? J. Int. Manag. 2009, 15, 460-474. [CrossRef]

110. Balabanis, G.; Diamantopoulos, A.; Mueller, R.D.; Melewar, T.C. The Impact of Nationalism, Patriotism and Internationalism on Consumer Ethnocentric Tendencies. J. Int. Bus. Stud. 2001, 32, 157-175. [CrossRef]

111. Calhoun, M.A. Unpacking liability of foreignness: Identifying culturally driven external and internal sources of liability for the foreign subsidiary. J. Int. Manag. 2002, 8, 301-321. [CrossRef]

112. Hennart, J.F. Theories of the Multinational Enterprise. In The Oxford Handbook of International Business; Rugman, A.M., Ed.; Oxford University Press: Oxford, UK, 2009.

113. Gaur, A.S.; Lu, J.W. Ownership Strategies and Survival of Foreign Subsidiaries: Impacts of Institutional Distance and Experience. J. Manag. 2007, 33, 84-110. [CrossRef]

114. Sethi, D.; Judge, W. Reappraising liabilities of foreignness within an integrated perspective of the costs and benefits of doing business abroad. Int. Bus. Rev. 2009, 18, 404-416. [CrossRef] 
115. Asmussen, C.G.; Pedersen, T.; Dhanaraj, C. Host-country environment and subsidiary competence: Extending the diamond network model. J. Int. Bus. Stud. 2009, 40, 42-57. [CrossRef]

116. Pattnaik, C.; Elango, B. The Impact of Firm Resources on the Internationalization and Performance Relationship: A Study of Indian Manufacturing Firms. Multinatl. Bus. Rev. 2009, 17, 69-88. [CrossRef]

117. Rangan, S.; Drummond, A. Explaining outcomes in competition among foreign multinationals in a focal host market. Strateg. Manag. J. 2003, 25, 285-293. [CrossRef]

118. Phillips, N.; Tracey, P.; Karra, N. Rethinking institutional distance: Strengthening the tie between new institutional theory and international management. Strateg. Organ. 2009, 7, 339-348. [CrossRef]

119. Meyer, J.W.; Rowan, B. Institutionalized Organizations: Formal Structure as Myth and Ceremony. Am. J. Sociol. 1977, 83, 340-363. [CrossRef]

120. Zucker, L.G. Institutional Theories of Organization. Annu. Rev. Sociol. 1987, 13, 443-464. [CrossRef]

121. DiMaggio, P.J.; Powell, W.W. The Iron Cage Revisited: Institutional Isomorphism and Collective Rationality in Organizational Fields. Am. Sociol. Rev. 1983, 48, 147-160. [CrossRef]

122. Salomon, R.; Wu, Z. Institutional distance and local isomorphism strategy. J. Int. Bus. Stud. 2012, 43, 343-367. [CrossRef]

123. Miller, S.R.; Eden, L. Local Density and Foreign Subsidiary Performance. Acad. Manag. J. 2006, 49, $341-355$. [CrossRef]

124. Etzkowitz, H.; Leydesdorff, L. The Dynamics of Innovation: From National Systems and "Mode 2" to a Triple Helix of University-Industry-Government Relations. Res. Policy 2000, 29, 109-123. [CrossRef]

125. Carayannis, E.G.; Barth, T.D.; Campbell, D.F.J. The Quintuple Helix innovation model: Global warming as a challenge and driver for innovation. J. Innov. Entrep. 2012, 1, 2. [CrossRef]

126. Doloreux, D. What we should know about regional systems of innovation. Technol. Soc. 2002, 24, $243-263$. [CrossRef]

127. Kang, B. The innovation process of Huawei and ZTE: Patent data analysis. China Econ. Rev. 2015, 36, 378-393. [CrossRef]

128. Attaran, A. How Do Patents and Economic Policies Affect Access to Essential Medicines in Developing Countries? Health Aff. 2004, 23, 155-166. [CrossRef]

129. Quach, U.; Thorsteinsdóttir, H.; Renihan, J.; Bhatt, A.; Von Aesch, Z.C.; Singer, P.A.; Daar, A.S. Biotechnology patenting takes off in developing countries. Int. J. Biotechnol. 2006, 8, 43-59. [CrossRef]

130. Speer, K. Patent Protection for Pharmaceuticals: Ensuring Access to Enabling Innovation. Health Law Policy Brief 2011, 5, 39-50.

131. Goldberg, P.K. Intellectual Property Rights Protection in Developing Countries: The Case of Pharmaceuticals. J. Eur. Econ. Assoc. 2010, 8, 326-353. [CrossRef]

132. Pouris, A.; Pouris, A. Patents and economic development in South Africa: Managing intellectual property rights. S. Afr. J. Sci. 2011, 107, 1-10. [CrossRef]

133. Thompson, M.A.; Rushing, F.W. An Empirical Analysis of the Impact of Patent Protection on Economic Growth: An Extension. J. Econ. Dev. 1999, 24, 67-76.

134. Lazzarotti, V.; Manzini, R. Different modes of open innovation: A theoretical framework and an empirical study. Int. J. Innov. Manag. 2009, 13, 615-636. [CrossRef]

(C) 2019 by the authors. Licensee MDPI, Basel, Switzerland. This article is an open access article distributed under the terms and conditions of the Creative Commons Attribution (CC BY) license (http://creativecommons.org/licenses/by/4.0/). 